\title{
HepaCAM inhibits the malignant behavior of castration-resistant prostate cancer cells by downregulating Notch signaling and PF-3084014 (a $\gamma$-secretase inhibitor) partly reverses the resistance of refractory prostate cancer to docetaxel and enzalutamide in vitro
}

\author{
ZHONGBO DU ${ }^{1 *}$, LUO LI $^{2 *}$, WEI SUN ${ }^{1,3}$, XIAO WANG ${ }^{1}$, YAO ZHANG $^{1}$, ZHIXIONG CHEN $^{1}$, \\ MENGJUAN YUAN ${ }^{1,3}$, ZHEN QUAN $^{1}$, NANJING LIU ${ }^{2}$, YANNI HAO ${ }^{2}$, TING LI $^{2}$, \\ JINHUA WANG ${ }^{1}$, CHUNLI LUO ${ }^{2}$ and XIAOHOU WU ${ }^{1}$ \\ ${ }^{1}$ Department of Urology, The First Affiliated Hospital of Chongqing Medical University; \\ ${ }^{2}$ Key Laboratory of Laboratory Medical Diagnostics, Ministry of Education, Department of Laboratory Medicine, \\ Chongqing Medical University, Chongqing 400016; ${ }^{3}$ Department of Urology, \\ Fuling Center Hospital of Chongqing City, Chongqing 408000, P.R. China
}

Received November 21, 2017; Accepted April 4, 2018

DOI: $10.3892 /$ ijo.2018.4370

\begin{abstract}
Castration-resistant prostate cancer (CRPC) continues to be a major challenge in the treatment of prostate cancer (PCa). The expression of hepatocyte cell adhesion molecule (HepaCAM), a novel tumor suppressor, is frequently downregulated or lost in PCa. Overactivated Notch signaling is involved in the development and progression of $\mathrm{PCa}$, including CRPC. In this study, we found that the activities of Notch signaling were elevated, while HepaCAM expression was decreased in CRPC tissues compared with matched primary prostate cancer (PPC) tissues. In addition, HepaCAM negativity was found to be associated with a worse progression-free survival (PFS). Furthermore, the overexpression of HepaCAM induced by transfection with a HepaCAM overexpression vector (Ad-HepaCAM) exerted antitumor effects
\end{abstract}

Correspondence to: Professor Chunli Luo, Key Laboratory of Laboratory Medical Diagnostics, Ministry of Education, Department of Laboratory Medicine, Chongqing Medical University, 1 Yixueyuan Road, Yuzhong, Chongqing 400016, P.R. China

E-mail: luochunli79@126.com

Professor Xiaohou Wu, Department of Urology, The First Affiliated Hospital of Chongqing Medical University, 1 Youyi Road, Yuzhong, Chongqing 400016, P.R. China

E-mail: 112751265@qq.com

${ }^{*}$ Contributed equally

Key words: castration-resistant prostate cancer, hepatocyte cell adhesion molecule, Notch signaling, PF-3084014, enzalutamide, docetaxel by decreasing the proliferation, and suppressing the invasion and migration of bicalutamide-resistant (Bica-R) cells and enzalutamide-resistant (Enza-R) cells. Importantly, we found that the antitumor effects of HepaCAM on the resistant cells were associated with the downregulation of Notch signaling. Moreover, we revealed that PF-3084014 (a $\gamma$-secretase inhibitor) re-sensitized Enza-R cells to enzalutamide, and sequential dual-resistant (E+D-R) cells to docetaxel. Additionally, the findings of this study demonstrated that the use of PF-3084014 alone exerted potent antitumor effect on the resistant cells in vitro. On the whole, this study indicates that HepaCAM potentially represents a therapeutic target and PF-3084014 may prove to a promising agent for use in the treatment of refractory $\mathrm{PCa}$.

\section{Introduction}

Although the latest statistics suggest that the overall incidence of prostate cancer ( $\mathrm{PCa}$ ) has rapidly declined in the United States, accounting for approximately one-half of total decline in male cancers (1), PCa still remains a major health concern in developed countries. In addition, the mortality rate associated with PCa is rising at a rate of 5\% per year in China (2). Androgen deprivation therapy (ADT), such as abiraterone and enzalutamide (mainly bicalutamide in China), is a mainstream treatment strategy. The treatments are initially effective for patients. However, the relief is temporary and castration-resistant prostate cancer (CRPC) emergences within a few years (3). Chemotherapeutic agents, such as docetaxel and cabazitaxel, are considered to be the preferred treatment strategy following resistance to ADT $(4,5)$. However, sequential dual-resistance to androgen receptor (AR) axis inhibitors and taxanes occurs with a lethal outcome within a few months $(6,7)$. However, there are few therapeutic approaches available with which to 
combat the sequential dual-resistant PCa. Thus, the development of novel therapeutic strategies with which to combat refractory $\mathrm{PCa}$ is urgently required.

Hepatocyte cell adhesion molecule (HepaCAM), a member of the Ig superfamily, was first proven to be decreased or undetectable in hepatocellular carcinoma (8). HepaCAM exerts a marked antitumor effect by inhibiting proliferation, inducing apoptosis and suppressing migration in multiple cancer types (9-16). In our previous study, it was reported that HepaCAM downregulates AR, leading to the suppression of the biological behavior of PCa cell lines (17). However, the role of HepaCAM remains unknown in CRPC. Moreover, as HepaCAM has been identified to decrease AR amplification, which is responsible for castration resistance, we wished to determine whether HepaCAM can reverse the resistance of the resistant cells to the AR axis inhibitor, enzalutamide.

The Notch signaling pathway has been proven to be associated with cell differentiation, proliferation and apoptosis (18). Furthermore, the constitutive expression of the Notch intracellular domain (NICD) has been shown to suppress the apoptosis of luminal epithelial cells and stimulate luminal cell proliferation in the prostate $(18,19)$. Overactivated Notch signaling has been found in $\mathrm{PCa}$, including CRPC, which promotes PCa progression $(20,21)$. The downregulation of Notch has been shown to significantly inhibit the proliferation, invasion and migration of PCa cells in vitro (22-25). PF-3084014, a $\gamma$-secretase inhibitor, suppresses Notch activity by blocking NICD formation, and results in the inhibition of tumor cells in diverse cancer types (26-28). However, it is unclear as to whether PF-3084014 exerts an antitumor effect on the resistant cells. A recent study demonstrated that PF-3084014 restores the sensitivity of docetaxel-resistant PCa cells to docetaxel through the downregulation of Notch signaling in vitro and in vivo (22). However, it is unknown as to whether PF-3084014 restores the sensitivity of enzalutamide-resistant (Enza-R) cells to enzalutamide, and sequential dual-resistant (E+D-R) cells to docetaxel.

In this study, we detected the expression of HepaCAM in matched primary prostate cancer (PPC) and CRPC tissues, and observed the differences in the expression of HepaCAM, Notch1 and Hes1 between the matched PPC and CRPC specimens. We further explored the correlations between the HepaCAM and Notch axis in CRPC tissues and cell lines. Additionally, we evaluated the sensitivities of Enza-R and $\mathrm{E}+\mathrm{D}-\mathrm{R}$ cells to enzalutamide and docetaxel, respectively following the downregulation of Notch activity by overexpressing HepaCAM and/or treatment with PF-3084014. The findings of this study may provide a novel treatment approach for patients with refractory PCa.

\section{Materials and methods}

Patients and tissue samples. Patients were included in this study by our inclusion standard as follows: i) All patients met the EAU guidelines for confirming CRPC (29). Serum testosterone levels at castration levels $(<1.7 \mathrm{nmol} / \mathrm{l})$ plus either: a) Three consecutive increases in serum prostate-specific antigen (PSA) levels, 1 week apart, leading to two $50 \%$ increases over the nadir with PSA levels $>2.0 \mathrm{ng} / \mathrm{ml}$; b) the appearance of new lesions and the progression of the primary lesion: New bone lesions and a soft tissue lesion (including prostate, bladder neck, seminal vesicle and other viscera) using TRUS or/and MRI. ii) All patients had available matched PPC and CRPC specimens. iii) All patients had complete clinical data, including PPC and CRPC data. If patients met the inclusion standard ' $i$ ', the tissues obtained from the prostate lesions were regarded as CRPC specimens (30). According to the inclusion standard, 45 CRPC and 41 matched PPC samples (4 cases with clinical data of PPC, but without PPC tissue specimens) were collected at the Department of Urology at the First Affiliated Hospital of Chongqing Medical University, Chongqing, China between April, 2008 and September, 2016. CRPC specimens of prostate lesions were obtained from the patients by transurethral resection of the prostate (TURP, 30 cases) or needle biopsy (15 cases). All samples were reviewed by a pathologist for the confirmation of PCa. Gleason's score was evaluated not only in the PPC tissues, but also in the CRPC tissues with the help of a pathologist who was blinded to the clinical data and assessed Gleason's scores in the tissue samples. This study was approved by the Ethics Committee of Chongqing Medical University. Informed consent was obtained from the patients or their family members who agreed to the use of their samples in this study.

Immunohistochemistry assay. All the embedded samples, including the 41 PPC specimens and 45 matched CRPC specimens (30 cases from TURP and 15 cases from needle biopsy), were cut into $5-\mu \mathrm{m}$-thick sections. The immunoreactivities of HepaCAM, Notch1 and Hes1 were detected using a standard immunoperoxidase staining procedure (anti-HepaCAM, 1:200; cat. no. 18177-1-AP; ProteinTech, Wuhan, China; anti-Notch1, 1:200, cat. no. ab52627; anti-Hes1, 1:200, cat. no. ab108937; both from Abcam, Cambridge, UK). Staining scoring was semi-quantitatively assessed using staining intensity and was defined as 0 , no staining; 1 , weak staining; 2 , light staining; 4 , moderate staining; and 6 and 8, strong staining. Staining scores of $\leq 1$ were regarded as negative expression, while staining scores of $\geq 2$ were regarded as positive expression.

Reverse transcription-quantitative PCR (RT-qPCR). Total RNA was extracted from all cell lines using TRIzol reagent, and reversed transcribed into cDNA using the Prime Script ${ }^{\mathrm{TM}} \mathrm{RT}$ reagent kit (both from Takara, Dalian, China). SYBR PremixEx Taq $^{\mathrm{TM}}$ II kit (Takara) was used for RT-qPCR with the CFX96 $6^{\mathrm{TM}}$ Real-Time PCR Detection System (Bio-Rad, Hercules, CA, USA). The sequences of the primers were as follows: HepaCAM sense, 5'-TACTGTAGATGTGCCCATTTCG-3' and antisense, 5'-CTTCTGGTTTCAGGCGGTC-3'; Notch1 sense, 5'-GAAC GGGGCUAACAAAGAUTT-3' and antisense, 5'-AUCUUU GUUAGCCCCGUUCTT-3'; Hes1 sense, 5'-GGACTAGTATGC CAGCTGATATAATGGAG-3' and antisense, 5'-GAAGATC TAGGTGGGCTAGGGACTTTAC-3'; Jagged1 sense, 5'-GTG CCGCCATAGGTAGAGT-3' and antisense, 5'-CCAGCCAAC CACAGAAAC-3'; and $\beta$-actin sense, 5'-TGACGTGGACAT CCGCAAAG-3' and antisense, 5'-CTGGAAGGTGGACAG CGAGG-3'. The thermocycling conditions of RT-qPCR were as follows: Initial denaturation, $95^{\circ} \mathrm{C}$ for $3 \mathrm{~min} ; 95^{\circ} \mathrm{C}$ for $10 \mathrm{sec}, 60^{\circ} \mathrm{C}$ for $20 \mathrm{sec}, 72^{\circ} \mathrm{C}$ for $20 \mathrm{sec}, 40$ cycles; final extension: $72{ }^{\circ} \mathrm{C}$ for $5 \mathrm{~min}$. The mRNA expression levels were calculated using the comparative $2^{-\Delta \Delta C q}$ method (31) and $\beta$-actin served as a calibrator. All gene expression experiments were repeated at least 3 times. 
Western blot analysis. Total protein was extracted from the cell lines (please see cell lines below) and tissue samples using RIPA buffer containing the phosphatase inhibitors, NaF and $\mathrm{Na}_{3} \mathrm{VO}_{4}$, and the protease inhibitor, PMSF (Beyotime Institute of Biotechnology, Beijing, China). The protein concentration was determined using the BCA Protein Assay kit (Beyotime Institute of Biotechnology). Protein samples (50 $\mu \mathrm{g})$, stacked by $5 \%$ SDS-PAGE and separated by 10 or $12 \%$ SDS-PAGE, were transferred to PVDF membranes (EMD Millipore, Billerica, MA, USA). After blocking with 5\% non-fat milk for $2 \mathrm{~h}$ at room temperature, the membranes were incubated with the following primary antibodies overnight at $4^{\circ} \mathrm{C}$ : Anti-E-Cadherin (1:1,000; cat. no. 3195), anti-N-cadherin (1:1,000; cat. no. 4061), anti-Snail (1:1,000; cat. no. 3895) were obtained from Cell Signaling Technology (Danvers, MA, USA). Anti-Jagged1 (1:1,000; cat. no. ab109536), anti-Notch1 (1:2,000; cat. no. ab52627), anti-NICD (1:500; cat. no. ab83232), anti-Hes1 (1:1,000; cat. no. ab108937) were from Abcam. Anti-HepaCAM (1:500; cat. no. 18177-1-AP) was purchased from ProteinTech. Anti-GAPDH (1:1,000; cat. no. 5174; Cell Signaling Technology) was used as loading control. The membranes were then incubated with the following secondary antibodies for $2 \mathrm{~h}$ at room temperature: Goat anti-mouse IgG (1:3,000; cat. no. SA00001-1), goat anti-rabbit IgG (1:3,000; cat. no. SA00001-2) (obtained from ProteinTech). The enhanced chemiluminescent (ECL) kit was purchased from Merck Millipore (Billerica, MA, USA). The intensity level of the protein expression bands was evaluated using Image-Pro plus 6.0.

Cells cell culture, treatment and transfection. Human prostate cell lines (RWPE-1, LNCaP and DU145) were obtained from the American Type Culture Collection (ATCC, Manassas, VA, USA). The 293A cell line was a gift from Professor Wenli Luo, Key Laboratory of Laboratory Medical Diagnostics, Ministry of Education, Department of Laboratory Medicine, Chongqing Medical University, Chongqing, China. All the cell lines were cultured in RPMI-1640 supplemented with $10 \%$ fetal bovine serum (FBS) (both from Gibco-Life Technologies, Carlsbad, CA, USA) and $1 \%$ penicillin/streptomycin (Beyotime Institute of Biotechnology). To generate bicalutamide-resistant cells and enzalutamide-resistant cells, the LNCaP cells, one of the androgen-dependent prostate cancer cell strains, were treated with enzalutamide $(10 \mu \mathrm{M})(32)$ and bicalutamide $(10 \mu \mathrm{M})$ (Selleck Chemicals, Houston, TX, USA), respectively for at least 6 months. For the generation of bicalutamide-resistant (Bica-R) cells, the cells were first cultured with $1 \mu \mathrm{M}$ (33), or 5,10 or $25 \mu \mathrm{M}$ (34) bicalutamide, respectively. We found that the concentration of $1 \mu \mathrm{M}$ bicalutamide had almost no effect on the LNCaP cells, and the concentration of $25 \mu \mathrm{M}$ bicalutamide killed too many cells to induce the cells continually (data not shown). Moreover, similar to treatment with $10 \mu \mathrm{M}$ enzalutamide, treatment with $10 \mu \mathrm{M}$ bicalutamide inhibited cell growth by 60 to $70 \%$ (data not shown). After screening, we selected the concentration of $10 \mu \mathrm{M}$ of bicalutamide by ourselves to generate Bica-R cells. The HepaCAM plasmid was transfected into 293A cells using Lipofectamine 2000 (Invitrogen; Thermo Fisher Scientific, Inc., Waltham, MA, USA) according to the manufacturer's instructions. Adenoviruses carrying HepaCAM (Ad-HepaCAM) were stored at $-80^{\circ} \mathrm{C}$ and amplified in $293 \mathrm{~A}$ cells. The viral fluid was obtained after freezing and thawing the 293A cells repeatedly. The prostate cancer cell strains were transfected with Ad-HepaCAM or Ad-GFP, respectively. After $72 \mathrm{~h}$ of incubation, follow-up experiments were performed. The cells were treated with the concentration of $5 \mu \mathrm{M} \mathrm{PF}-3084014$ for $48 \mathrm{~h}$ (Med Chem Express, Monmouth Junction, NJ, USA).

We also constructed docetaxel-resistant cells based on the LNCaP cell line and sequential dual-resistant cells to enzalutamide and docetaxel based on the Enza-R cells. The LNCaP and Enza-R cells were respectively incubated with various concentrations of docetaxel (0.1, 0.5, 1, 2 and $5 \mathrm{nM}$; Med Chem Express) and the growth of the cells was observed. We found that the concentrations of 0.1 and $0.5 \mathrm{nM}$ docetaxel were not able to inhibit cell growth effectively, and the concentrations of 2 and $5 \mathrm{nM}$ docetaxel killed too many cells to culture continuously (data not shown). Moreover, the concentration of $1 \mathrm{nM}$ docetaxel inhibited the growth of both the LNCaP and Enza-R cells by 60 to $70 \%$ (data not shown). Therefore, we selected the concentration of $1 \mathrm{nM}$ of docetaxel as the initial concentration of administration. The LNCaP and Enza-R cells were treated with $1 \mathrm{nM}$ docetaxel every $24 \mathrm{~h}$ for 3 weeks. Moreover, when the morphology of the cells exhibited alterations, such as cell membrane shrinkage and even disruption, and acquired a thin and small, polygonal shape, or the cells stopped growing, treatment was halted until the cells recovered. The drug concentration was increased when the cells were able to tolerate the current concentration. Each time the drug concentration was increased, some aliquots of cells were stored. When the cells were killed or contaminated, we resuscitated the aliquots. The frozen cells were removed from liquid nitrogen and placed in a $37^{\circ} \mathrm{C}$ water bath for $20-30 \mathrm{sec}$. The thawed cells were added to RPMI-1640. Following centrifugation $(1,000 \mathrm{rpm} ; 5 \mathrm{~min})$, the cells were incubated with a lower concentration of docetaxel. By the stepwise exposure method, the cells were cultured until they were able to tolerate $10 \mathrm{nM}$ docetaxel (35) in 2 months. The cells were maintained in $10 \mathrm{nM}$ docetaxel for at least 4 months. The docetaxel-resistant cells were termed Doce-R cells and sequential dual-resistant cells (resistant to enzalutamide and docetaxel) were termed E+D-R cells.

Cell counting kit-8 (CCK-8) assay. CCK-8 assay for cell viability, the cells were plated in 96 -well plates (2,000 cells/well), and incubated for $12 \mathrm{~h}$. The cells were then cultured with the various treatment agents in each 3 replicate wells. Each well was supplemented with $10 \mu \mathrm{l} \mathrm{CCK-8} \mathrm{reagent}$ (Beijing Solarbio Science \& Technology Co., Ltd., Beijing, China). Following incubation for $1 \mathrm{~h}$. Optical density was detected at absorbance of $450 \mathrm{~nm}$ using a microplate reader (Bio-Rad Laboratories, Inc., Hercules, CA, USA). CCK-8 assay for the half maximal inhibitory concentration $\left(\mathrm{IC}_{50}\right)$ of enzalutamide or docetaxel to the cells, the resistant cells (4,000 cells/ well) pretreated with various reagents, such as Ad-HepaCAM or Ad-GFP, were seeded into 96-well plates and incubated for $12 \mathrm{~h}$. The cells were then treated with various concentrations of enzalutamide or docetaxel in each 3 replicate wells for $24 \mathrm{~h}$. DMSO (Sigma-Aldrich; Thermo Fisher Scientific, Inc.) was used as the control. For CCK-8 assay for the viability of the Enza-R, Doce-R, E+D-R cells treated with PF-3084014, the 
cells $(4,000$ cells/well) were treated with increasing concentrations of PF-3084014 for $48 \mathrm{~h}(5,10,20,30,40,60,80$ and $100 \mu \mathrm{M})$ and DMSO for $48 \mathrm{~h}$ was used as the control.

Colony formation assay. The cells (400 cells/well) were plated in 6-well plates, and were consecutively cultured until the numbers of each clone reached 50 cells under a microscope (Nikon, Tokyo, Japan). The clones were stained with $0.05 \%$ crystal violet solution (Beyotime Institute of Biotechnology) for $20 \mathrm{~min}$ at room temperature. The colony formation experiments were performed at least 3 times.

Transwell and wound healing assay. For Transwell assay, $1.0 \times 10^{4}$ cells were plated in the upper chamber of the insert with Matrigel (BD Biosciences, San Jose, CA, USA). The cells were incubated with serum-free medium for $48 \mathrm{~h}$. The cells were then stained with $0.1 \%$ crystal violet and $4 \%$ formaldehyde (Beyotime Institute of Biotechnology). The number of cells, fixed on the bottom membrane of the inserts was counted under a microscope (Nikon). For wound healing assay, 5x10 cells/well were seeded into a 6 -well plate. Following $24 \mathrm{~h}$ of incubation, the cells were wounded with a yellow pipette tip. The cells were then cultured for $24 \mathrm{~h}$ and the wound healing was observed under a microscope (Nikon) at indicated time-points.

Immunofluorescence. A total of $1.0 \times 10^{5}$ cells/well were plated into a 12-well plate inserted with glass coverslips. Following incubation for $24 \mathrm{~h}$, the cells were fixed in $4 \%$ paraformaldehyde for $20 \mathrm{~min}$, and incubated with primary antibody (anti-Notch1 1:50; anti-Hes1, 1:100) (both from Abcam) overnight at $4^{\circ} \mathrm{C}$. The cells were then incubated with secondary antibody (Zhongshan Golden Bridge Biotechnology, Beijing, China) for $50 \mathrm{~min}$ in a dark room at room temperature. The cell nuclei were stained with DAPI (Zhongshan Golden Bridge Biotechnology) for $10 \mathrm{~min}$. Immunofluorescence images were obtained using a fluorescence microscope (Nikon).

Statistical analysis. Statistical analyses were performed using SPSS 19.0 software (IBM SPSS Corp., Armonk, NY, USA). All the numerical data are expressed as the means \pm SD. Data were analyzed using Kaplan-Meier survival analysis, one-way ANOVA, two-way ANOVA, the Student's t-test, Pearson's correlation analysis, Spearman's correlation analysis, the Mann-Whitney test, McNemer test, the Chi-square test for trend and Pearson's Chi-square test where appropriate. Values of $\mathrm{P}<0.05$ were considered to indicate statistically significant differences.

\section{Results}

HepaCAM negativity is associated with the upregulation of Notchl and Hes1 in CRPC samples. We collected 45 CRPC samples and 41 matched PPC samples (PPC specimens of 4 patients were unavailable) (Table I). The expression of HepaCAM was detected in the matched PPC and CRPC tissues by immunohistochemistry assay. In total, 71\% (32/45) of the CRPC samples exhibited HepaCAM negative staining (staining scores $\leq 1$ ), whereas HepaCAM expression was negative in $58 \%$ (24/41) of the matched PPC samples (Table I and Fig. 1A).
We then determine whether there were any differences in HepaCAM, Notch1 and Hes1 expression levels between the matched PPC and CRPC tissues. In comparison to the matched PPC tissues, the expression of HepaCAM was lost more frequently, $(\mathrm{P}=0.036$; Fig. 1A, panels 1 and 2, and $\mathrm{D})$, and the expression of Hes1 was upregulated $(\mathrm{P}=0.0237$; Fig. 1C, panels 1 and 2, and F) in the CRPC tissues. We failed to observe any differences in the expression of Notch1 between the matched PPC and CRPC tissues $(\mathrm{P}=0.063$; Fig. 1B, panels 1 and 2, and E). We also evaluated whether the loss of HepaCAM correlated with increased Notch1 and Hes1 expression levels in the CRPC samples using Pearson's linear correlation. As shown in Fig. $1 \mathrm{G}$ and $\mathrm{H}$, the loss of HepaCAM negatively correlated with an increase in Notch1 expression $(\mathrm{r}=-0.652, \mathrm{P}<0.01)$, as well as an increase in Hes1 expression $(\mathrm{r}=-0.442, \mathrm{P}=0.02)$. The results of western blot analysis revealed a similar result in 14 CRPC samples obtained by needle biopsy and TURP (part of the 45 CRPC samples) (Fig. 2A-C).

To examine the association between the protein expression of HepaCAM and dynamic alterations in gland morphology in the matched tissues, Gleason's score, a system for assessing gland morphology, was evaluated not only in the PPC tissues, but also in CRPC tissues with the help of a pathologist. Our data revealed that, compared to HepaCAM positivity in the CRPC tissues, HepaCAM negativity was associated with higher Gleason scores $(\mathrm{P}=0.011)$ (Table I), suggesting that HepaCAM plays an important role in maintaining normal gland morphology. Moreover, the loss of HepaCAM in the CRPC samples, but not in the matched PPC samples was found to be associated with bone metastases $(\mathrm{P}=0.001)$ (Table I) suggesting that patients with CRPC with HepaCAM negativity are prone to bone metastases. Kaplan-Meier survival analysis revealed that the median PFS was 39 months (95\% CI, 26-52 months) in the patients with CRPC with HepaCAM positivity, while the median PFS was 27 months (95\% CI, 20-34 months) in the HepaCAM-negative patients. HepaCAM negativity in the CRPC tissues was associated with a shorter PFS in the patients with CRPC ( $\mathrm{P}=0.039)$ (Fig. 2D).

Overexpression of HepaCAM suppresses the proliferation, invasion and migration of the resistant cells. In China, the cost of the use of enzalutamide is high, and thus the majority of patients cannot afford treatment with this agent. Patients with PCa are willing to be treated with bicalutamide. In this study, $78 \%$ of the patients $(35 / 45)$ were treated with bicalutamide (Table I). Enzalutamide is widely used in the treatment of $\mathrm{PCa}$ in developed countries. Therefore, in this study, we constructed both Bica-R cells and Enza-R cells, as described in the Materials and methods. Western blot analysis was performed to detect the expression levels of HepaCAM in the RWPE-1, LNCaP, Bica-R cells and Enza-R cells. As shown in Fig. 3A and B, HepaCAM was highly expressed in the RWPE1 cells, whereas it was almost undetectable in the other cell lines. To determine the role of HepaCAM in the proliferative capacity of the resistant cells, adenoviral vectors, carryuing the HepaCAM gene, were transfected into the LNCap, Bica-R and Enza-R cells, respectively (Fig. 3A and B). The results of CCK- 8 assay revealed that the overexpression of HepaCAM suppressed the proliferation of the DU145, LNCaP, Bica-R 
Table I. Demographic and clinical characteristics of the patients with castration-resistant prostate cancer.

\begin{tabular}{|c|c|c|c|c|}
\hline & \multirow[b]{2}{*}{$\begin{array}{c}\text { Overall } \\
n=45\end{array}$} & \multicolumn{2}{|c|}{ HepaCAM } & \multirow[b]{2}{*}{ P-value } \\
\hline & & $\begin{array}{c}\text { Negative } \\
32 / 45(71 \%)\end{array}$ & $\begin{array}{c}\text { Positive } \\
13 / 45(29 \%)\end{array}$ & \\
\hline Age, years & & & & $\mathrm{P}=0.93^{\mathrm{a}}$ \\
\hline Median & 73 & 74 & 71 & \\
\hline Quartiles 25-75 & $63-78$ & $62-78$ & $64-76$ & \\
\hline PSA of PPC $\mu \mathrm{g} / 1$ & $\mathrm{n}=45$ & $24 / 41^{\mathrm{e}}$ & $17 / 41$ & $\mathrm{P}=0.27^{\mathrm{a}}$ \\
\hline Median & 92.49 & 134.61 & 71.19 & \\
\hline Quartiles 25-75 & 28.34-239.4 & $63.06-195.00$ & $19.83-186.15$ & \\
\hline PSA of CRPC $\mu \mathrm{g} / 1$ & $\mathrm{n}=45$ & $32 / 45$ & $13 / 45$ & $\mathrm{P}=0.14^{\mathrm{a}}$ \\
\hline Median & 39.98 & 37.85 & 41.47 & \\
\hline Quartiles 25-75 & $19.32-152.9$ & $17.79-99.50$ & $23.55-198.50$ & \\
\hline Gleason score of PPC & $\mathrm{n}=45(\%)$ & $24 / 41(\%)$ & $17 / 41(\%)$ & $\mathrm{P}=0.41^{\mathrm{b}}$ \\
\hline$\leq 6$ & $18 / 45(40)$ & $8 / 24(33)$ & $7 / 17(41)$ & \\
\hline 7 & $14 / 45(31)$ & $7 / 24(29)$ & $6 / 17(35)$ & \\
\hline$\geq 8$ & $13 / 45(29)$ & $9 / 24(38)$ & $4 / 17(24)$ & \\
\hline Gleason score of CRPC & & $32 / 45(\%)$ & $13 / 45(\%)$ & $P=0.011^{b}$ \\
\hline$\leq 6$ & $6 / 45(13)$ & $2 / 32(6)$ & $4 / 13(31)$ & \\
\hline 7 & $10 / 45(22)$ & $6 / 32(19)$ & $4 / 13(31)$ & \\
\hline$\geq 8$ & $29 / 45(65)$ & $24 / 32(75)$ & $5 / 13(38)$ & \\
\hline \multicolumn{5}{|l|}{ Metastases sites of PPC } \\
\hline Bone & $11 / 45(24)$ & $7 / 11(64)$ & 4/11 (36) & $\mathrm{P}=0.263^{\mathrm{c}}$ \\
\hline Nodle & $10 / 45(22)$ & $4 / 10(40)$ & $6 / 10(60)$ & $\mathrm{P}=0.388^{\mathrm{c}}$ \\
\hline Visceral & $15 / 45(33)$ & $6 / 15(40)$ & $9 / 15(60)$ & $\mathrm{P}=0.791^{\mathrm{c}}$ \\
\hline \multicolumn{5}{|l|}{ Metastases sites of CRPC } \\
\hline Bone & $32 / 45(71)$ & $26 / 32(81)$ & 6/32 (19) & $\mathbf{P}=0.001^{c}$ \\
\hline Drugs for initial treatment & $\mathrm{n}=45(\%)$ & $32 / 45$ & $13 / 45$ & $\mathrm{P}=0.607^{\mathrm{d}}$ \\
\hline Bicalutamide & $35 / 45(71)$ & $26 / 32(81)$ & $9 / 13(69)$ & \\
\hline Other durgs & $10 / 45(29)$ & 6/32 (19) & $4 / 13(31)$ & \\
\hline
\end{tabular}

PSA, prostate-specific antigen; PPC, primary prostate cancer; CRPC, castration-resistant prostate cancer. ${ }^{\mathrm{a}} \mathrm{Mann}$-Whitney test for 2 independent variables; ${ }^{\text {b }} \mathrm{Chi}$-square test for trend for the number of rows or columns $>2$; ${ }^{\mathrm{c}} \mathrm{McNemer}$ test for comparing the differences between the matched categorical variables; ${ }^{\mathrm{d}}$ Pearson's Chi-square test for 2 groups of independent variables; ${ }^{\mathrm{e}}$ represents that tissue specimens of 4 patients with PPC were lost but clinical data was available; ${ }^{f}$ generally, Gleason's score is not judged after hormonal therapy. To investigate the association between the expression of HepaCAM protein and dynamic changes in the gland morphology in the matched PPC and CRPC tissues, Gleason's score was evaluated not only in PPC tissues, but also in CRPC tissues with the help of a pathologist. Numbers in bold font indicate statistical significance.

and Enza-R cells (Fig. 3C-F). The results of colony formation assay revealed similar results (Fig. 4A). To explore the role of HepaCAM in the invasion and migration of the resistant cells, Transwell assay and wound healing assay were performed using the Bica-R and Enza-R cells. The data revealed that the overexpression of HepaCAM inhibited the invasion and migration of the resistant cells (Fig. 4B and C).

It is well known that AR amplification is responsible for CRPC. Our previous study revealed that HepaCAM decreased the expression of AR (17). Thus, we hypothesized that HepaCAM may reverse the resistance of Enza-R cells to enzalutamide via the downregulation of $\mathrm{AR}$. The $\mathrm{IC}_{50}$ value of enzalutamide for the Enza-R cells was determined by CCK-8 assay. Unexpectedly, however, we failed to observe any significant changes in the resistance of the Enza-R cells to enzlutamide when HepaCAM was overexpressed (Fig. 4D).

HepaCAM suppresses the biological behavior of the resistant cells through the downregulation of Notch signaling. As mentioned above, the expression of HepaCAM negatively correlated with Notch signaling in the CRPC samples (Figs. 1G-H and 2A-C). Thus, we hypothesized that HepaCAM may inhibit the proliferation and invasion of the resistant cells through the downregulation of the Notch signaling pathway.

We also investigated members of Notch signaling by western blot analysis and RT-qPCR in the LNCaP and CRPC cells. We found that the levels of Jagged1, Notch1, NICD (protein level) and Hes1 were enhanced in the resistant 
A

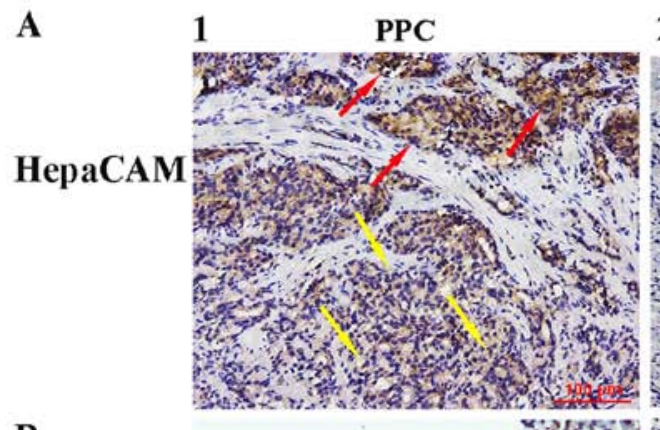

2 Matched CRPC

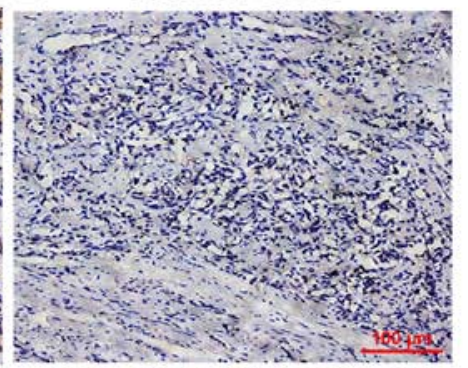

B

C
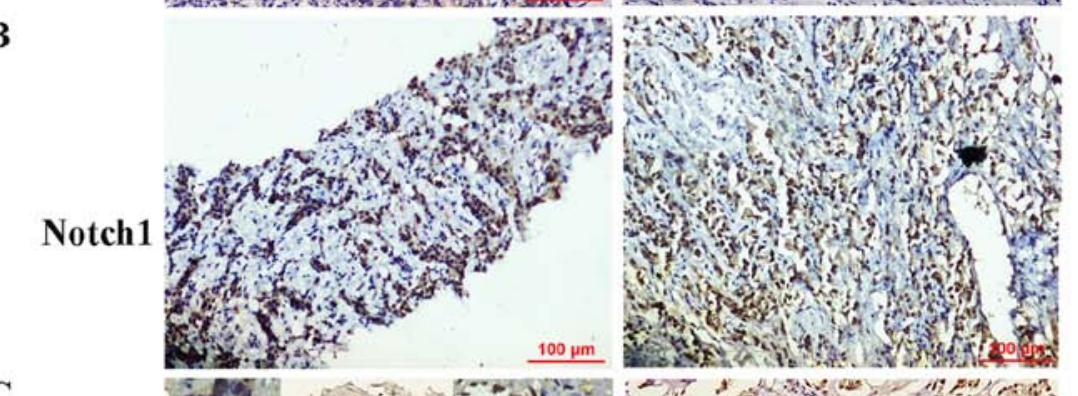

$100 \mathrm{\mu m}$
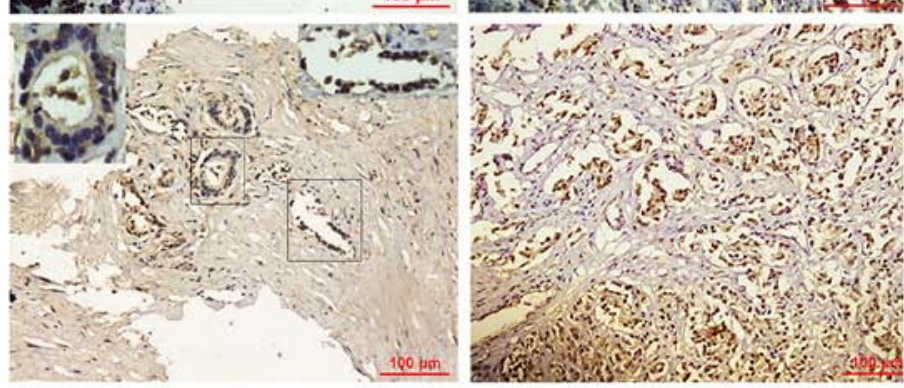

D

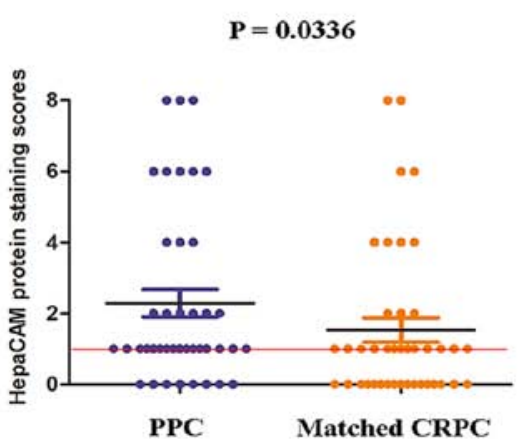

$\mathbf{E}$

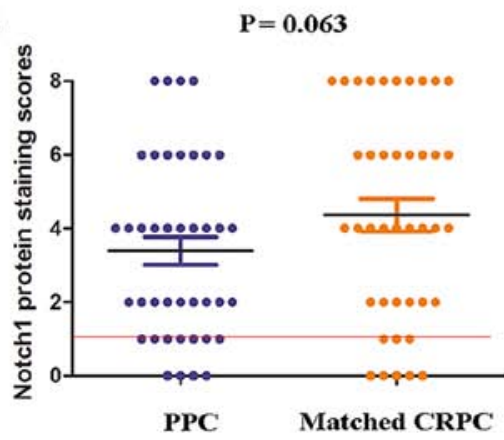

G

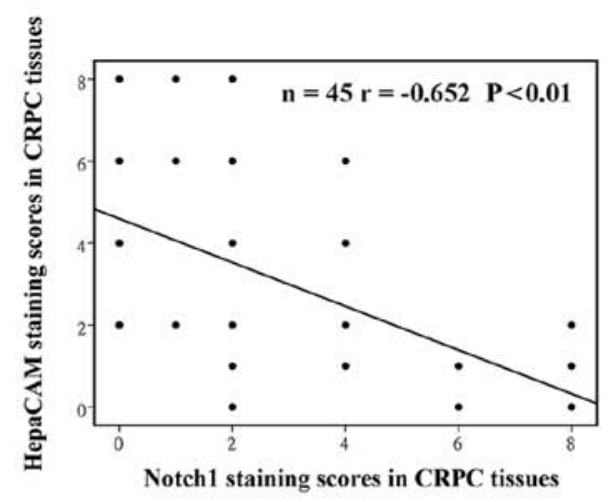

$\mathbf{H}$

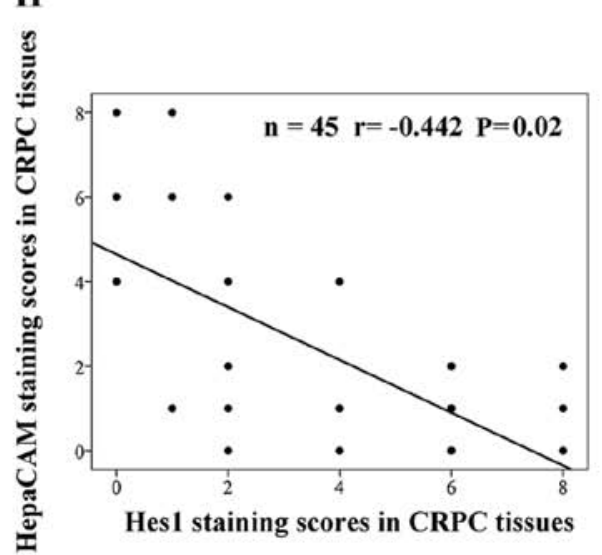

$\mathbf{F}$

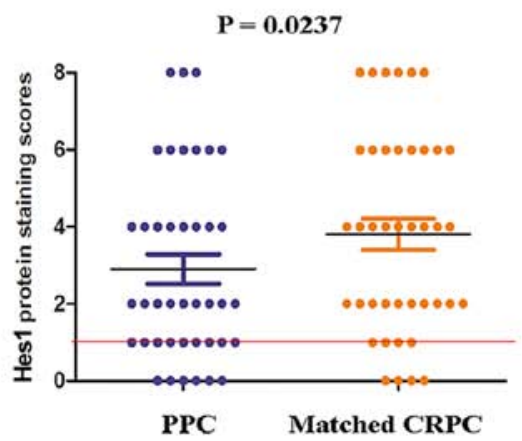

Figure 1. The expression levels of HepaCAM, Notch1 and Hes1 in matched primary prostate cancer (PPC) and castration-resistant prostate cancer (CRPC) samples. (A, panel 1) Moderate staining of HepaCAM in sites where the gland structures were presented (red arrows), and weak staining of HepaCAM in sites where the gland structures disappeared (yellow arrows) (magnification, x200). (A, panel 2) The staining of HepaCAM was undetectable in CRPC tissues (magnification, x200). (B, panel 1) Needle biopsy sample with moderate staining of Notch1 in PPC tissues (magnification, x200). (B, panel 2) Prostatectomy specimen with strong staining of Notch1 in CRPC tissues (magnification, x200). (C, panel 1) Hes1 protein was weakly expressed in sites where the gland structure was presented (upper left-hand corner, $\mathrm{x} 400$ ) and was moderately expressed in sites where the gland structure was disorganized (upper right-hand corner; magnification, 400). (C, panel 2) Strong nuclear positivity of Hes1 in CRPC tissues (magnification, x400). (D-F) Average staining scores for HepaCAM Notch1 and Hes1 in matched PPC and CRPC tissues. ( $\mathrm{G}$ and $\mathrm{H}$ ) The correlation curve analysis for HepaCAM staining scores versus Notch1 and Hes1 staining scores in CRPC tissues. Values of $\mathrm{P}<0.05$ were considered to indicate statistically significant differences.

cells (Fig. 5A-C). To determine the role of Notch signaling in the resistant cells, we treated the Enza-R cells with $5 \mu \mathrm{M}$ PF-3084014 (a $\gamma$-secretase inhibitor) for $48 \mathrm{~h}$, which maintains Notch signaling in inactivation. As shown in Fig. 5D, PF-3084014 induced a decrease in Enza-R cell viability, suggesting that Notch signaling plays an important role in $\mathrm{PCa}$ cells which are resistant to treatment. Moreover, when used in combination with Ad-HepaCAM and $5 \mu \mathrm{M}$ PF-3084014, the viability of the Enza-R cells was inhibited more significantly than the use of either reagent alone (Fig. 5D). Furthermore, we found that the combination of Ad-HepaCAM and PF-3084014 exerted a more potent promoting effect on the protein expression of E-cadherin, and a more potent suppressive effect on the protein expression of $\mathrm{N}$-cadherin and Snail (Fig. 5E and F). Taken together, these findings indicated a synergistic suppressive effect of HepaCAM and PF-3084014 on the proliferation and migration of $\mathrm{PCa}$ cells which are resistant to treatment.

We then determined the possible mechanisms responsible for the suppressive effects of HepaCAM overexpression on the survival of PCa cells which are resistant to treatment. The results of immunofluorescence assay revealed that the overexpression of HepaCAM decreased Notch1 and Hes1 
A

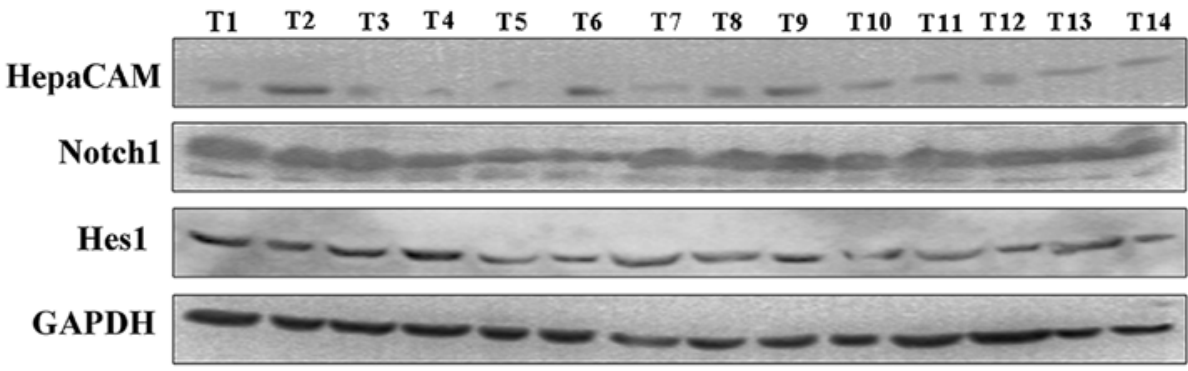

B

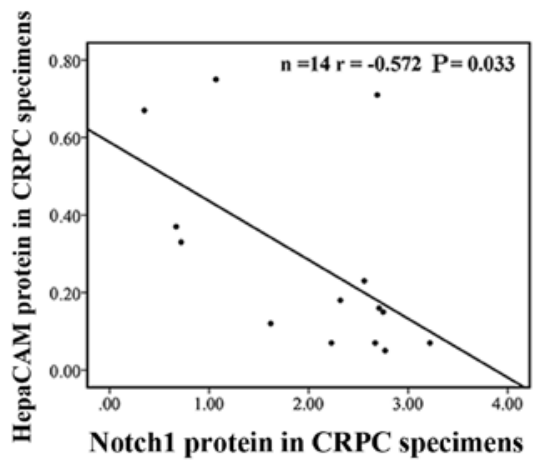

C

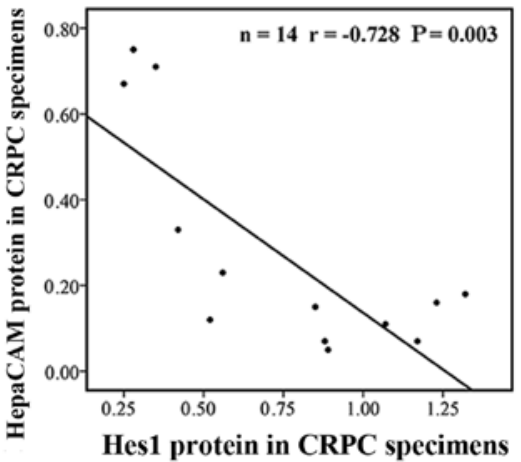

D

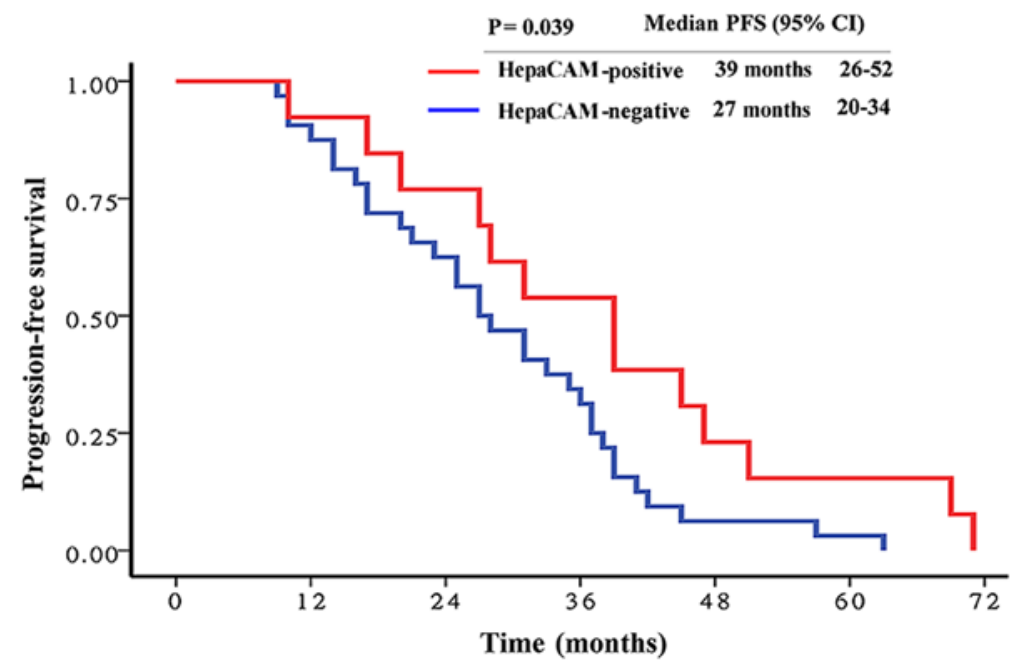

Figure 2. (A) Western blot analysis for 14 castration-resistant prostate cancer (CRPC) specimens obtained by needle biopsy and prostate resection; GAPDH was used as a loading control. (B and C) Correlation curve analysis for HepaCAM protein versus corresponding Noth1 and Hes1 protein in CRPC specimens using Pearson's linear correlation analysis. Values of $\mathrm{P}<0.05$ were considered to indicate statistically significant differences. (D) Kaplan-Meier survival analysis of the progression-free survival (PFS) of 45 patients with CRPC (32 patients with HepaCAM negativity, 13 patients with HepaCAM positivity); CI, confidence interval.

expression in the Enza-R cells, which was similar to the effects of PF-3084014. Importantly, when the cells were treated with a combination of Ad-HepaCAM and PF-3084014, the expression levels of Notch1 and Hes1 were downregulated more significantly. Note that in order for Fig. 6 to be more concise, the panels for DAPI staining alone are not shown (Fig. 6A). Western blot analysis and RT-qPCR were performed to further determine the mechanisms responsible for the suppressive effects of HepaCAM overexpression on the viability of the resistant cells. As shown in Fig. B-E, both the mRNA and protein levels of Jagged1, Notch1, NICD (only the protein level) and Hes1 were downregulated when the resistant cells were treated with Ad-HepaCAM or/and PF3084014. Taken together, our data indicated that HepaCAM inhibited the biological behavior of the PCa cells which are resistant to treatment via the downregulation of Notch signaling.

Construction of docetaxel-resistant cells and sequential dual-resistant cells (resistant to enzalutamide and docetaxel). A recent study indicated that overactivated Notch signaling plays an important role in the resistant of PCa to docetaxel, and that the downregulation of Notch reverses docetaxel resistance (22). The results of this study revealed that the overexpression of HepaCAM downregulated Notch signaling in the resistant cells. Thus, we hypothesized that the downregulation of Notch signaling induced by the overexpression of HepaCAM possibly re-sensitizes the docetaxel-resistant cells to docataxel, instead of re-sensitizing the Enza-R cells to enzalutamide. 
A

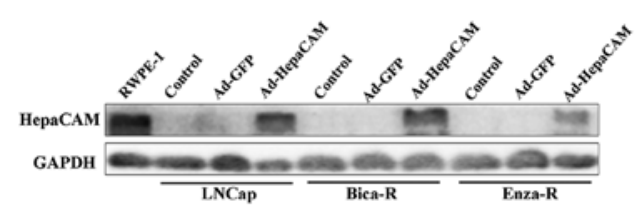

C

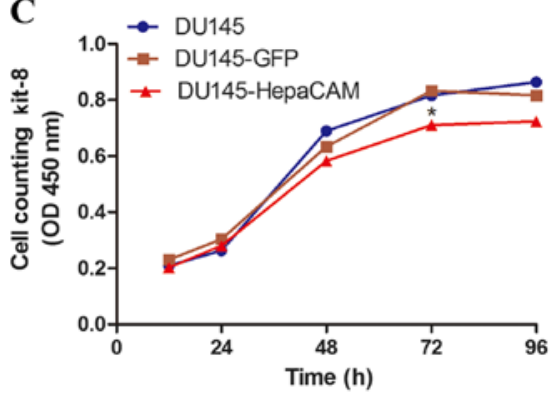

$\mathbf{E}$

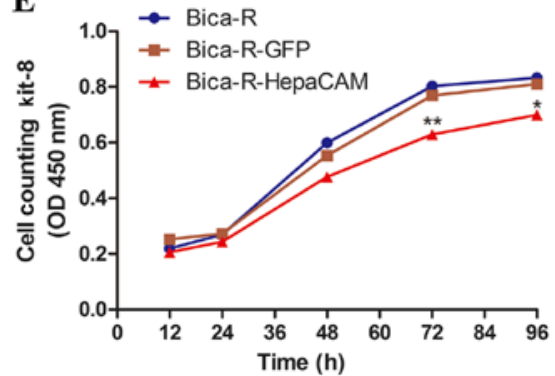

B $\square$ Control $₫$ Ad-GFP $\square$ Ad-HepaCAM

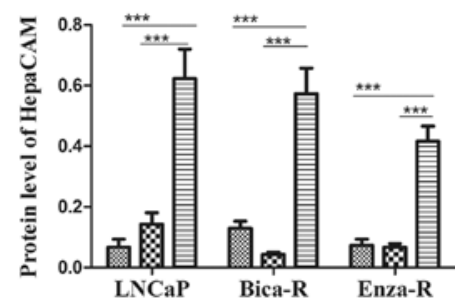

D

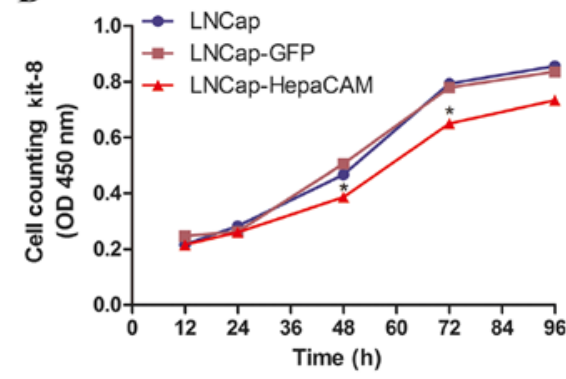

$\mathbf{F}$

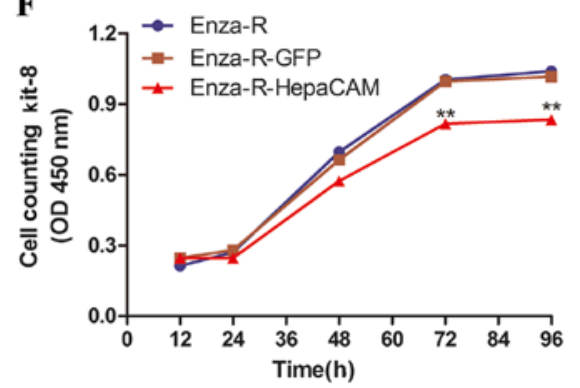

Figure 3. Overexpression of HepaCAM inhibits the growth of prostate cancer cells which are resistant to treatment. (A and B) Overexpression of HepaCAM was induced by transfecting adenovirus containing HepaCAM into human prostate cell lines and resistant cells. ${ }^{* * *} \mathrm{P}<0.001$. (C-F) The viability of DU145, LNCaP, Bica-R and Enza-R cells was measured by CCK-8 assay after treating the cells with Ad-HepaCAM for $72 \mathrm{~h}$ ("P<0.05, "P $<0.01$, compared to 'Ad-GFP' at the same time-points). Bica-R, bicalutamide-resistant LNCaP cells; Enza-R, enzalutamide-resistant LNCaP cells.

A
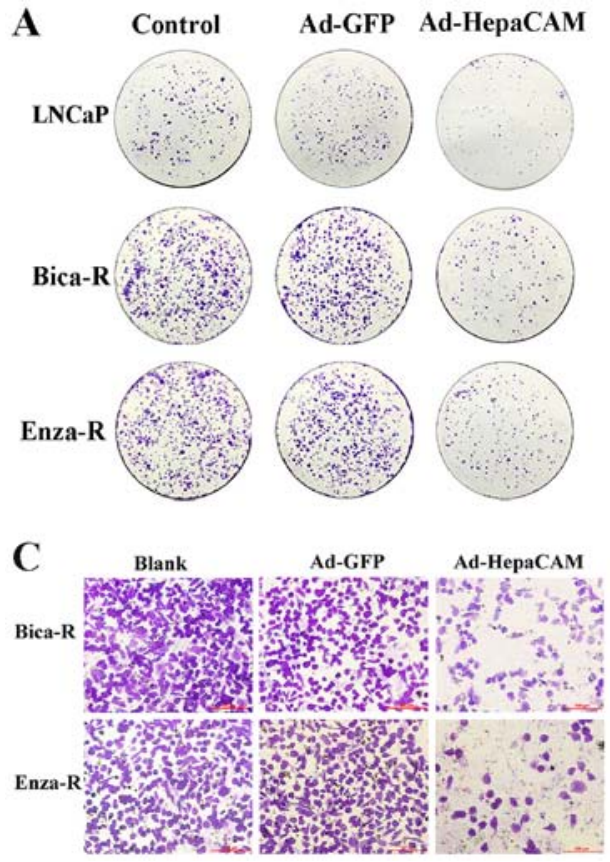

\section{B}

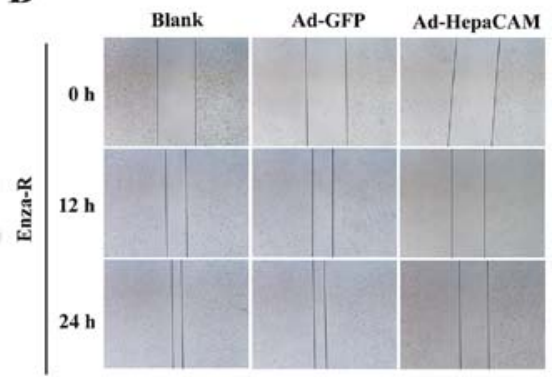

$\begin{array}{lll}D & \text { LNCaP } & I C_{50}: 1.33 \pm 0.46 \mu \mathrm{M} \\ & \text { Enza-R } & I_{50}: 133.51 \pm 45.17 \mu \mathrm{M} \\ & \pm \text { Enza-R+Ad-GFP } & I_{50}: 119.30 \pm 14.90 \mu \mathrm{M}\end{array}$

$\begin{array}{lll}\text { Enza-R+Ad-GFP } & I_{50}: 119.30 \pm 14.90 \mu \mathrm{M} \\ \text { Enza-R+Ad-HepaCAM } \quad \mathrm{IC}_{50}: 105.09 \pm 27.67 \mu \mathrm{M}\end{array}$

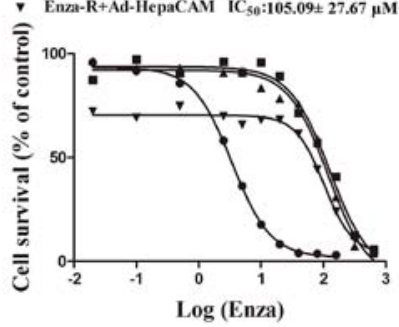

Figure 4. Overexpression of HepaCAM inhibits the invasion and migration of prostate cancer cells which are resistant to treatment. (A) Colony-forming efficiency of Bica-R, Enza-R cells and their parental cells after 10 days of culture; the cells were transfected with Ad-GFP and Ad-HepaCAM for $72 \mathrm{~h}$ (B) The migratory capacity of the Enza-R cells was evaluated by wound healing assay; the cells were transfected with Ad-GFP or Ad-HepaCAM for $72 \mathrm{~h}$. (C) Transwell assay was performed to examine the invasive ability of the Bica-R and Enza-R cells following transfection with Ad-GFP or Ad-HepaCAM for $72 \mathrm{~h}$ (magnification, $\mathrm{x} 400$ ). (D) LNCaP and Enza-R cells were exposed to increasing concentrations of enzalutamide for $48 \mathrm{~h}$, and the half maximal inhibitory concentration $\left(\mathrm{IC}_{50}\right)$ was determined by CCK-8 assay. Bica-R, bicalutamide-resistant LNCaP cells; Enza-R, enzalutamide-resistant LNCaP cells. 
A

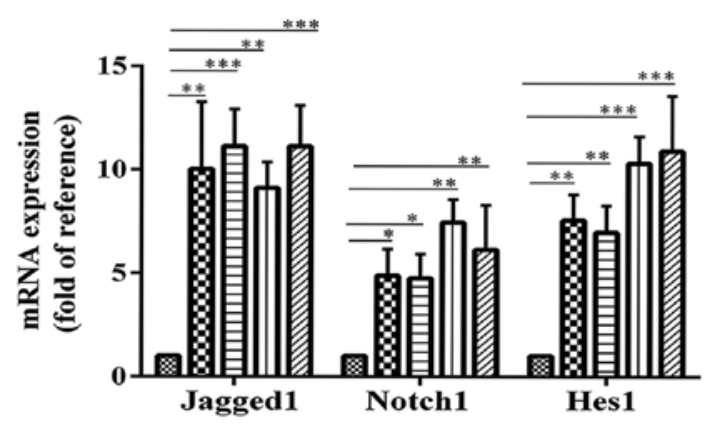

B
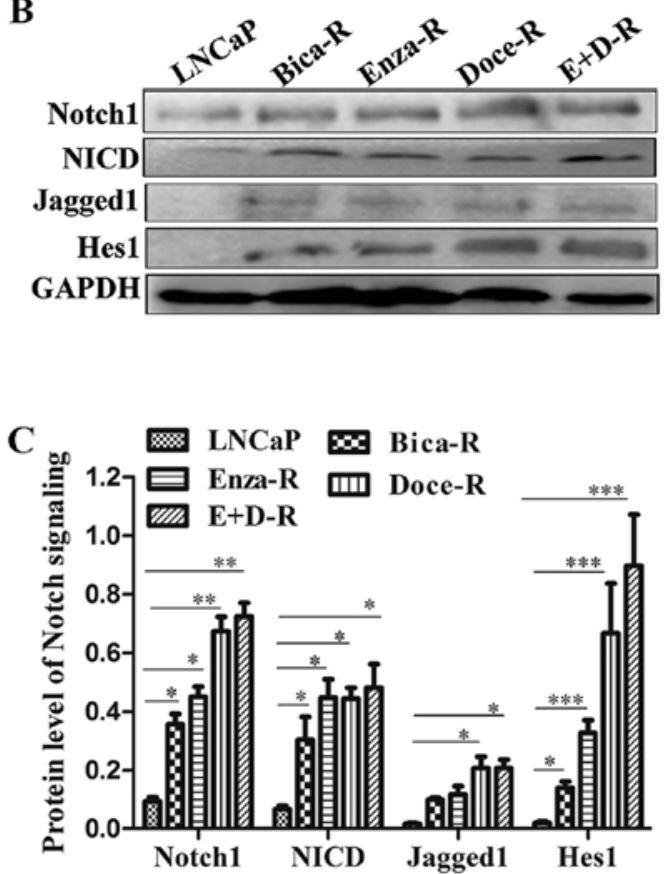

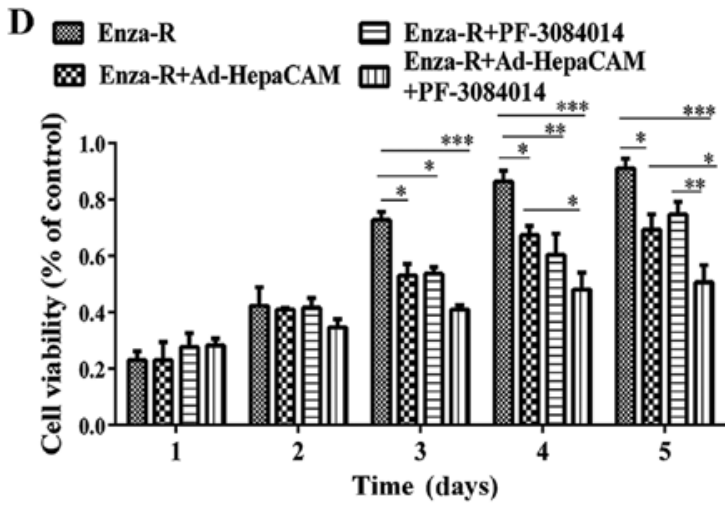

$\mathbf{E}$

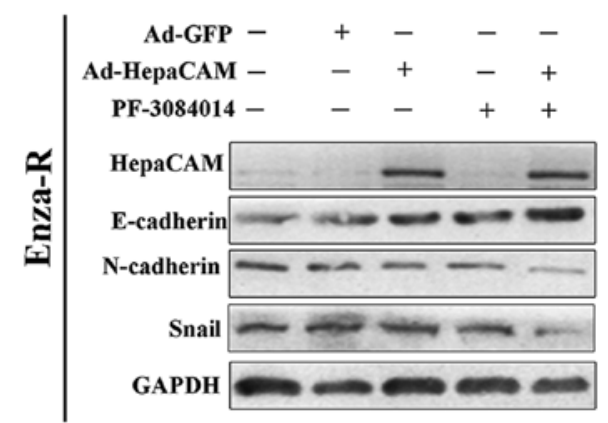

F

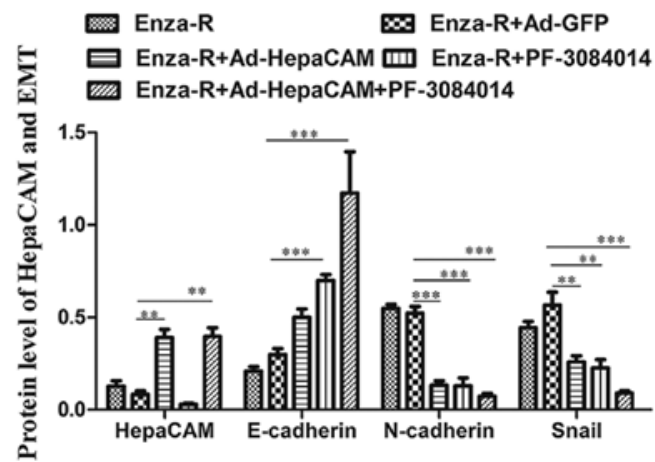

Figure 5. Notch signaling is upregulated in the resistant cells. (A) The mRNA levels of Notch1, Jagged1 and Hes1 in LNCap, Bica-R, Enza-R, Doce-R and E+D-R cells were detected by RT-qPCR. (B and C) The protein levels of Jagged1, Notch1, NICD and Hes1 in LNCap, Bica-R, Enza-R, Doce-R and E+D-R cells were evaluated by western blot analysis. (D) Cell viability of Enza-R cells was measured by CCK-8 assay following transfection with Ad-GFP or Ad-HepaCAM for $72 \mathrm{~h}$ and/or $5 \mu \mathrm{M}$ PF-3084014 for $48 \mathrm{~h}$. (E and F) The expression of E-cadherin, N-cadherin and Snail in Enza-R cells was examined by western blot analysis. The cells were transfected with Ad-GFP or Ad-HepaCAM for $72 \mathrm{~h}$ and treated with $5 \mu \mathrm{M}$ PF-3084014 for $48 \mathrm{~h}$. GAPDH served as a loading control. Bica-R, bicalutamide-resistant LNCaP cells; Enza-R, enzalutamide-resistant LNCaP cells; Doce-R, docetaxel-resistant LNCaP cells; E+D-R, sequential dual-resistant LNCap cells (resistant to enzalutamide and docetaxel); ${ }^{*} \mathrm{P}<0.05,{ }^{* *} \mathrm{P}<0.01$ and ${ }^{* * * *} \mathrm{P}<0.001$.

To confirm our hypothesis, we constructed Doce-R cells and sequential dual-resistant cells (resistant to enzalutamide and docetaxel) (E+D-R cells) as described in the Materials and methods. The $\mathrm{IC}_{50}$ values of docetaxel for the Doce-R, E+D-R and their parental cells were evaluated by CCK-8 assay. As shown in Fig. 7A and B, compared to their parental cells, the LNCaP, Doce-R cells exhibited an 81-fold increase in their resistance to docetaxel, whereas the E+D-R cells displayed a 56-fold increase in their resistance to docetaxel, compared to the Enza-R cells. Moreover, our data indicated that docetaxel inhibited the viability of both the LNCaP and Enza-R cells within the same range of concentrations, indicating that there was no cross-resistance between enzalutamide and docetaxel (Fig. 7A and B).

HepaCAM overexpression fails to re-sensitize the Doce- $R$ and $E+D-R$ cells to docetaxel, and $P F-3084014$ partly restores the sensitivity of the Enza-R, $E+D-R$ cells to enzalutamide and docetaxel, respectively in vitro. Our data indicated that the overexpression of HepaCAM suppressed the proliferation of both the Doce-R and E+D-R cells (Fig. 7C-E). When the cells were treated with PF-3084014 followed by Ad-HepaCAM, the inhibitory effects were enhanced in the E+D-R cells (Fig. 7E). However, we failed to observe that the overexpression of HepaCAM restores the sensitivity of the Doce- $R$ and E+D-R cells to docetaxel (Figs. 7A and B, and 8B and C). After the Enza-R and E+D-R cells were treated with $5 \mu \mathrm{M}$ PF-3084014 for $48 \mathrm{~h}$, the $\mathrm{IC}_{50}$ values of enzalutamide and docetaxel were determined by CCK- 8 assay, respectively. Surprisingly, we found that PF-3084014 restored the sensitivity of the Enza-R cells to enzalutamide by 4-fold, and that of the E+D-R cells to docetaxel by 7-fold (Fig. 8A and C) indicating that PF-3084014 may be regarded as a sensitizer of docetaxel and enzalutamide in the treatment of refractory PCa. 
A

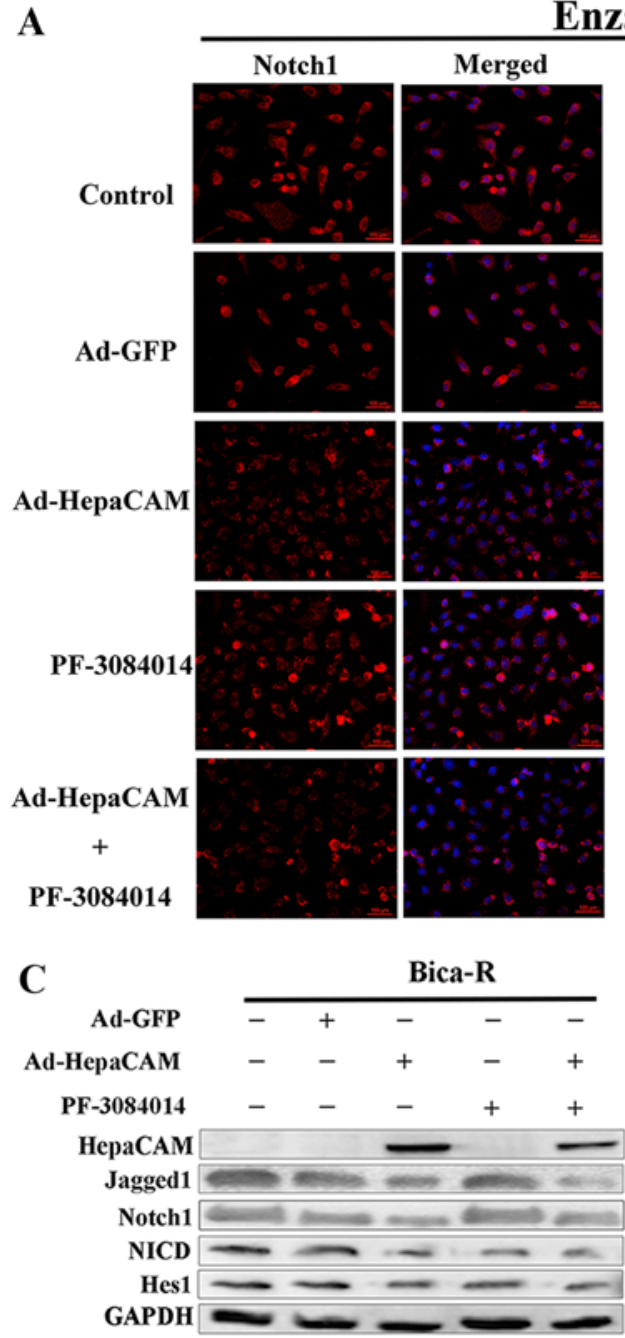

Enza-R
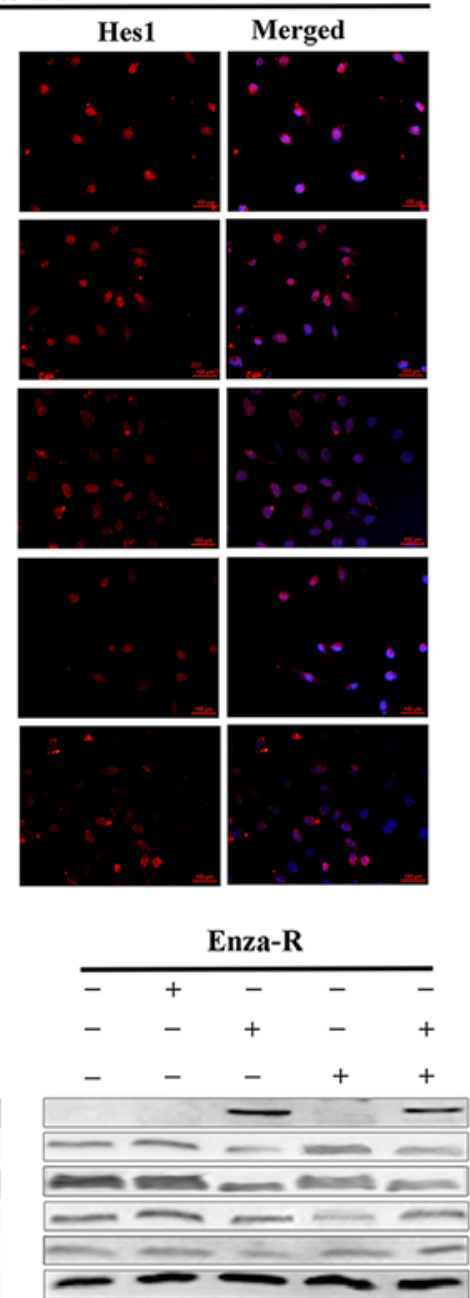

B

$$
\text { Control } \infty \text { Ad-GFP } \square \text { Ad-HepaCAM }
$$
血 PF-3084014 Ad-HepaCAM+PF-308041

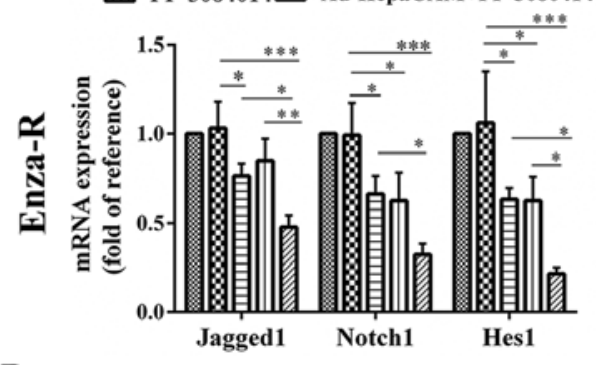
D Bica-R $\square$ Bica-R+Ad-HepaCAM Bica-R+Ad-GFP 四 Bica-R+PF-3084014 of Bica-R+Ad-HepaCAM+PF-3084014

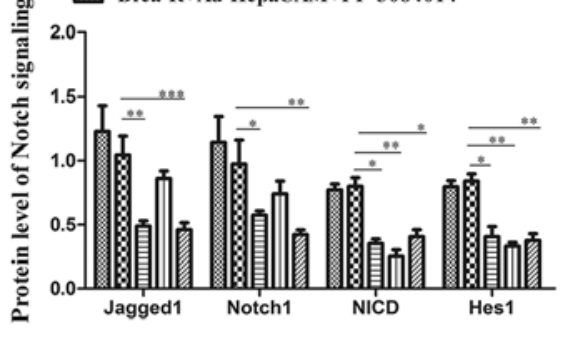

E Enza-R $\square$ Enza-R+Ad-HepaCAM Enza-R+Ad-GFP 四 Enza-R+PF-3084014
Enza-R+Ad-HepaCAM+PF-3084014

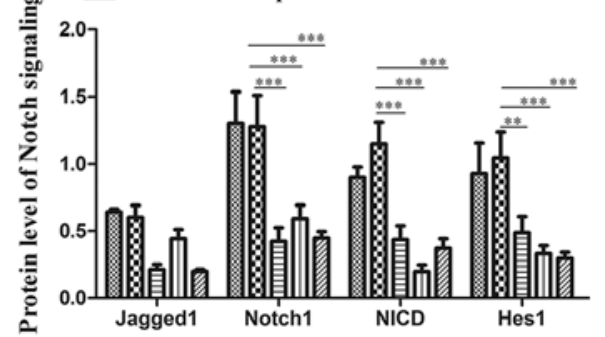

Figure 6. Overexpression of HepaCAM downregulates Notch signaling. (A) Notch1 and Hes1 were detected by immunofluorescence assay; cell nuclei were stained with DAPI (magnification, x200); in order for the figure to be more concise, the panels for DAPI staining alone are not shown. (B) RT-qPCR analysis of the mRNA expression levels of Notch1, Jagged1 and Hes1 in the Enza-R cells cultured alone or transfected with Ad-HepaCAM (72 h) and/or treated with $5 \mu \mathrm{M}$ PF-3084014 (48 h). (C-E) The protein levels of Jagged1, Notch1, NICD and Hes1 in Bica-R and Enza-R cells were detected by western blot analysis; GAPDH served as a loading control. Bica-R, bicalutamide-resistant LNCaP cells; Enza-R, enzalutamide-resistant LNCaP cells; Doce-R, docetaxel-resistant LNCaP cells; E+D-R, sequential dual-resistant LNCap cells (resistant to enzalutamide and docetaxel); ${ }^{*} \mathrm{P}<0.05,{ }^{* *} \mathrm{P}<0.01$ and ${ }^{* * *} \mathrm{P}<0.001$.

To determine whether PF-3084014 exerts antitumor effect on refractory $\mathrm{PCa}, \mathrm{CCK}-8$ assay was performed to evaluate the viability of the Enza-R, Doce-R and E+D-R cells following treatment with various concentrations of PF-3084014 (5, 10, $20,30,40,60,80$ and $100 \mu \mathrm{M})$ for $48 \mathrm{~h}$. The results revealed that, at an increasing concentration, PF-3084014 exerted a gradual but potent antitumor effect on the Enza-R, Doce-R and E+D-R cells (Fig. 8D-F), indicating that PF-3084014 may be considered as a novel therapy for refractory PCa.

\section{Discussion}

Cell adhesion molecules have been studied for many years in various types of cancer. Some studies have indicated that some adhesion molecules, such as CEACAM5 and CEACAM6 play important roles in tumor initiation and progression (36,37). Other adhesion molecules, such as CEACAM1 and CEACAM1-4S have been shown to exert anti-proliferative effects on some cancer types (38-40). For example, a high expression of CEACAM1-4S has been detected in normal breast epithelial cells; however, its expression is lost in breast cancer cells (MCF7). With the enforced expression of CEACAM1-4S, MCF7 cells have been shown to return to a morphological phenotype in Matrigel, which is similar to normal breast acini (38). In this study, HepaCAM, one of the cell adhesion molecules, was found to be expressed in PPC tissues where gland structures were presented. However, the expression of HepaCAM was downregulated in sites where gland structures were disorganized. Moreover, when gland structures disappeared, it was undetectable (Fig. 1A, panels 1 and 2). In addition, HepaCAM negativity in the CRPC tissues was associated with more severe Gleason scores. Therefore, we hypothesized that HepaCAM, similar to CEACAM1-4S, may be associated with maintaining the normal morphological phenotype of prostate epithelial cells. We aim to confirm this hypothesis in follow-up experiments.

In the present study, we also found that the loss of HepaCAM was more frequent in CRPC tissues than that in matched PPC tissues (Table I and Fig. 1A and D). This finding suggested that, along with tumor progression and the emergence of castration 

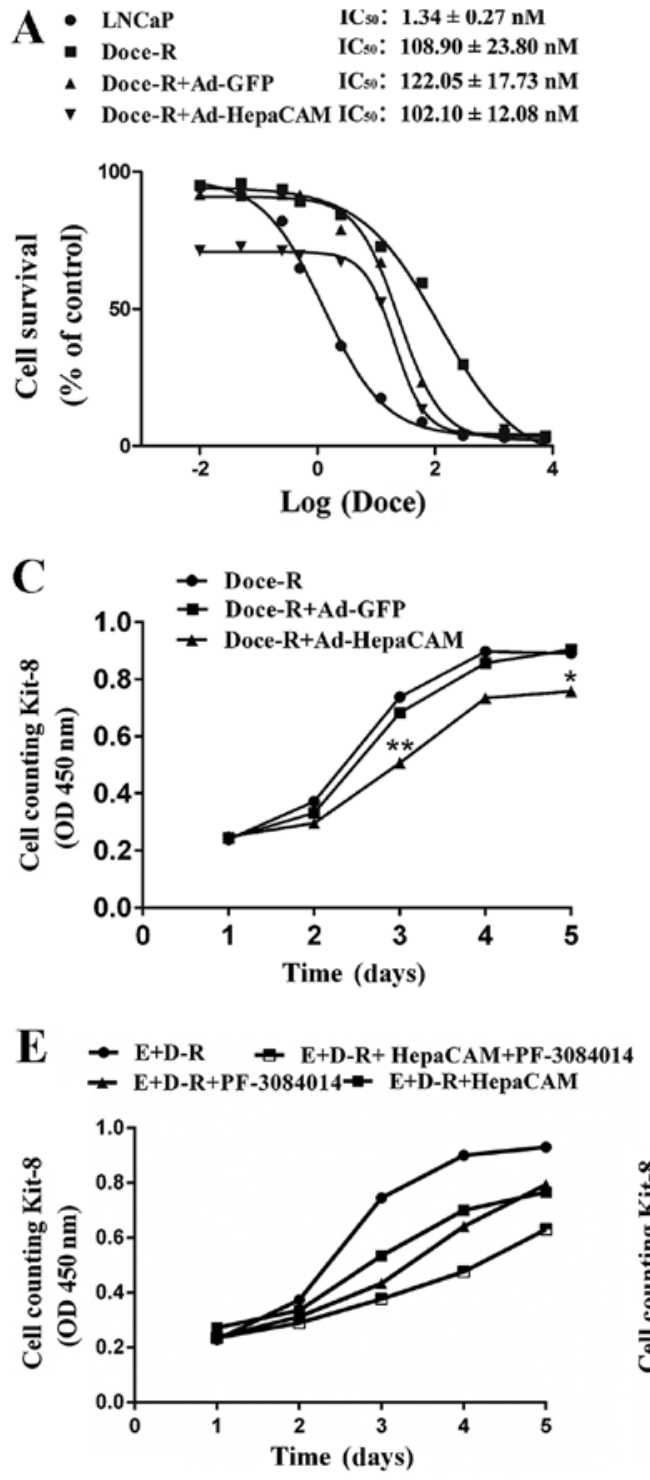
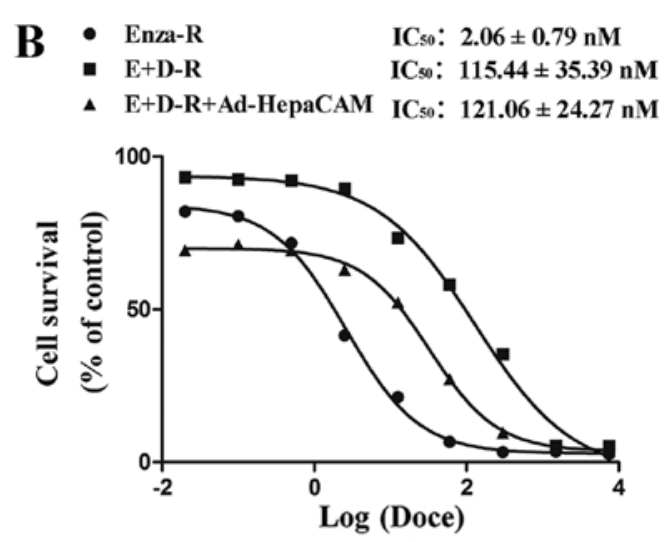

D

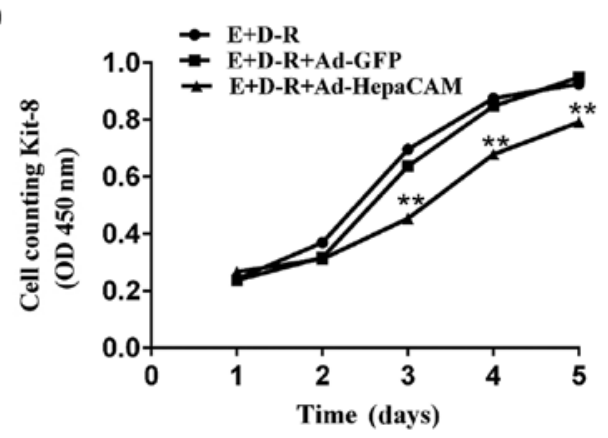

E+D-R E+D-R+PF-3084014

(-HepaCAM+PF-3084014

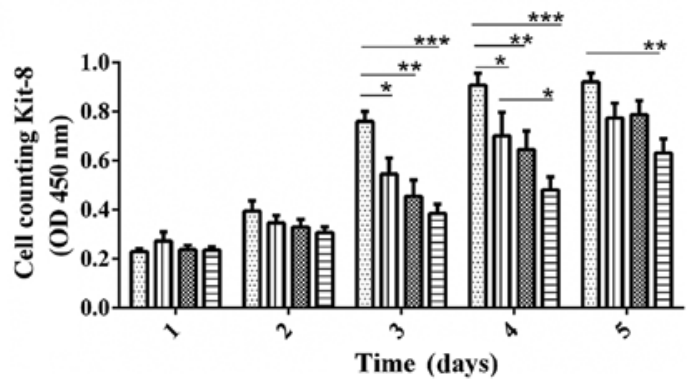

Figure 7. Overexpression of HepaCAM fails to re-sensitize the resistant cells to docetaxel, but inhibitsthe growth of the cells. (A and B) Doce-R, D+E-R and their parental cells were exposed to increasing concentrations of docetaxel for $48 \mathrm{~h}$, and the half maximal inhibitory concentration ( $\mathrm{IC}_{50}$ ) was determined by CCK-8 assay. The cells were transfected with Ad-GFP or Ad-HepaCAM for $72 \mathrm{~h}$. (C and D) Cell viability was evaluated by CCK-8 assay every $24 \mathrm{~h}$ for 5 days. The Doce-R and E+D-R cells were transfected with Ad-GFP or Ad-HepaCAM for $72 \mathrm{~h}$. (E) E+D-R cells were transfected with Ad-HepaCAM for 72 h and/or treated with PF-3084014 for $48 \mathrm{~h}$ and cell viability was evaluated by CCK-8 assay. ${ }^{*} \mathrm{P}<0.05,{ }^{* *} \mathrm{P}<0.01$ and ${ }^{* * * *} \mathrm{P}<0.001$. Enza-R, enzalutamide-resistant $\mathrm{LNCaP}$ cells; Doce-R, docetaxel-resistant LNCaP cells; E+D-R, sequential dual-resistant LNCaP cells (resistant to enzalutamide and docetaxel).

resistance, the downregulation and loss of HepaCAM gradually and continuously occurs over a few years. Importantly, our data demonstrated that HepaCAM negativity was associated with a shorter PFS in patients with CRPC (Fig. 2D). The results suggested that the loss of HepaCAM was associated with the poor prognosis of patients with CRPC. In the future, we aim to analyze the overall survival (OS) when the death endpoint occurs in patients with CRPC.

The activities of Notch signaling have been proven to be elevated in PCa $(20,21)$. More interestingly, Notch activities are more intensive in specimens of metastatic PCa than in specimens of PPC $(41,42)$. The findings of this study yielded a similar result in that Notch signaling was markedly increased in CRPC samples in compared to matched PPC tissues, indicating that Notch signaling plays an important role in the emergence and progression of CRPC. A recent study revealed that Notch signaling was upregulated in patients with docetaxel-resistant
PCa, and inhibiting Notch signaling eliminates subpopulation of the cells which are responsible for docetaxel resistance and delays the initiation of the resistance (43). In present study, Notch signaling was upregulated in the Bica-R, Enza-R, Doce-R and E+D-R cells (Fig. 5A and B). When HepaCAM was overexpressed, mRNA and protein levels of Notch were decreased. The viability and growth of the cells was decreased, suggesting that HepaCAM exerted antitumor effects through the downregulation of Notch activity in refractory PCa.

HepaCAM, an upstream cellular regulator, is involved in the regulation of many cell signaling pathways. For example, the knockdown of interleukin-6 (IL-6) upregulates HepaCAM expression via the STAT3/DNMTs axis, and reduces the proliferation of renal cell carcinoma cells (15). HepaCAM also increases the proportion of c-Myc phosphorylation in human renal carcinoma cells (44). The overexpression of HepaCAM downregulates $\mathrm{p}-\mathrm{AKT}$ and $\mathrm{p}$-FoxO expression, 

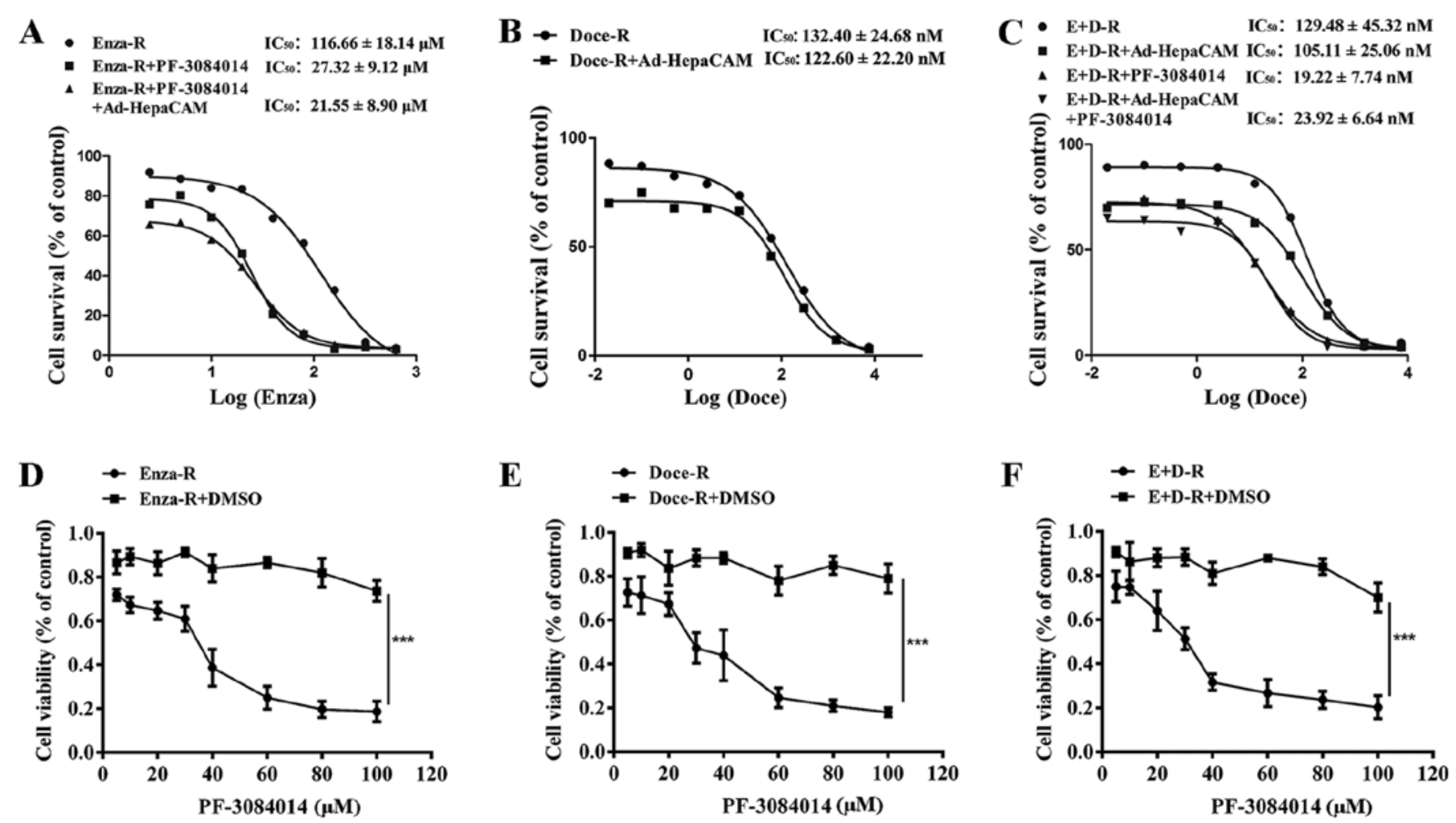

Figure 8. PF-3084014 re-sensitizes the resistant cells to the corresponding drugs, and exerts an antitumor effect on the resistant cells. (A-C) Enza-R, Doce-R and E+D-R cells were exposed to increasing concentrations of enzalutamide and docetaxel for $48 \mathrm{~h}$, respectively, and the half maximal inhibitory concentration $\left(\mathrm{IC}_{50}\right)$ was determined by CCK-8 assay. The cells were transfected with Ad-HepaCAM for $72 \mathrm{~h}$ and/or treated with PF-3084014 for $48 \mathrm{~h}$. (D-F) Enza-R, Doce-R and E+D-R cells were treated with increasing concentrations of PF-3084014 (5, 10, 20, 30, 40, 60, 80 and $100 \mu \mathrm{M})$ or DMSO for 48 h. Cell viability was detected by CCK-8 assay. ${ }^{* * *} \mathrm{P}<0.001$. Enza-R, enzalutamide-resistant LNCaP cells; Doce-R, docetaxel-resistant LNCaP cells; E+D-R, sequential dualresistant LNCaP cells (resistant to enzalutamide and docetaxel).

and inhibits the proliferation and viability of bladder cancer cells (45). Moreover, in glioblastoma cells, HepaCAM is able to keep stabilizing connexin 43 protein, a well-established tumor suppressor, and enhances its localization to the plasma membrane at cellular junctions (46).

$\mathrm{AR}$ axis inhibitors remain the major therapeutic strategies for patients with PCa $(47,48)$. However, the inevitable transition from hormone-sensitive PCa (HSPC) to CRPC remains an ever-present challenge in the treatment of PCa. When ADT fails and CRPC develops, docetaxel has been proven to prolong the OS of patients with CRPC (49). However, docetaxel resistance occurs within a few months. However, there are no effective approaches for dual-resistant PCa. In the present study, in order to observe the sequential dual resistance to AR axis inhibitors and taxanes, we constructed sequential dual-resistant cells (E+D-R) for the first time, at least to the best of our knowledge. As shown by our data (Fig. 7D and E), the overexpression of HepaCAM suppressed the growth of E+D-R cells, indicating that HepaCAM possibly represents a novel therapeutic target for patients with refractory $\mathrm{PCa}$.

PF-3084014, a $\gamma$-secretase inhibitor, has displayed antitumor activity in several types of cancer, such as breast cancer (50) and acute lymphoblastic leukemia (26). It has entered clinical trials for the treatment of multiple tumors $(26,51,52)$. More surprisingly, in a recent study, PF-3084014 was used in a phase II clinical trial for patients with advanced desmoid tumors, and clinical benefits with no instances of progressive disease and measurable regression in tumor volume were observed in 11 of
17 patients (53). A recent study also revealed that PF-3084014 sensitized docetaxel-resistant cells to docetaxel both in vitro and in vivo (22). In present study, we revealed that PF-3084014 also partly restored sensitivity of the E+D-R, Enza-R cells to docetaxel and to enzalutamide in vitro, suggesting that PF-3084014, as sensitizer of both enzalutamide and docetaxel, may be a novel adjuvant drug for use in the treatment of refractory PCa.

Unexpectedly, we failed to prove that the overexpression of HepaCAM restored the sensitivity of the Enza-R, Doce-R and E+D-R cells to corresponding drugs. A previous study demonstrated that Notch4 activation, but not Notch1 and Notch2, rendered MCF7 cells unresponsive to tamoxifen (54). Another study demonstrated that the upregulation of Notch4, but not Notch1, was responsible for tamoxifen resistance in specific breast cancer. The downregulation of Notch4 by MRK-003 (another $\gamma$-secretase inhibitor) has also been shown to reverse tamoxifen resistance and the hormone-dependent phenotype (55). In our opinion, Notch4, not Notch1, may also be responsible for the resistance of Enza-R and E+D-R cells. PF-3084014 partly reverses resistance by decreasing Notch4. However, HepaCAM may only affect Notch1, but not Notch4, resulting in failing to restore sensitivity of Doce-R, E+D-R cells to docetaxel.

Importantly, we further revealed that the use of PF-3084014 alone exerted an antitumor effect in vitro, suggesting that PF-3084014 may be not only function as a sensitizer, but may also be a promising reagent for use in the treatment of 
refractory PCa. Our results were not consistent with a those of a previous study (22), in which the use of PF-3084014 alone did not exert an antitumor effect on docetaxel-resistant cells. This may be explained by the fact that these authors treated the cells with a constant concentration of PF-3084014, $5 \mu \mathrm{M}$. However, when the cells were treated with $20 \mu \mathrm{M}$ PF-3084014, as in this study, its antitumor effect was highlighted (Fig. 8D-F).

Taken together, the present study demonstrates the following: HepaCAM expression was lost and Notch signaling was excessively activated in the majority of CRPC tissues. HepaCAM negativity was associated with a worse PFS of patients with CRPC. HepaCAM exerted antitumor effects on CRPC cells through the downregulation of Notch signaling. More importantly, PF-3084014 partly restored the sensitivity of the Enza-R and E+D-R cells to enzalutamide and docetaxel, respectively.

\section{Acknowledgements}

The authors would like to thank Dr Dan Yang, Key Laboratory of Laboratory Medical Diagnostics, Ministry of Education, Department of Laboratory Medicine, Chongqing Medical University, Chongqing, China, for providing technical assistance with the immunohistochemistry and immunofluorescence assays.

\section{Funding}

This study was supported by a grant from the Natural Science Foundation of China (no. 81272572).

\section{Availability of data and materials}

All data generated or analyzed during this study are included in this published article.

\section{Authors' contributions}

ZD and XW designed the experiments. ZD, LL, YZ and WS collected the specimens and analyzed the clinical data. ZD, LL, MY, ZQ, YH, TL and JW carried out the experiments. ZD and LL co-wrote the manuscript. CL provided technical support of this research project and supervised the progress of the experiments. ZD, ZC, WS and NL analyzed statistical data. ZD, LL and XW assembled and installed the figures. All authors have read and approved the final manuscript.

\section{Ethics approval and consent to participate}

This study was approved by the Ethics Committee of Chongqing Medical University. Informed consent was obtained from the patients or their family members who agreed to the use of their samples in this study.

\section{Consent for publication}

Not applicable.

\section{Competing interests}

The authors declare that they have no competing interests.

\section{References}

1. Siegel RL, Miller KD and Jemal A: Cancer statistics, 2016. CA Cancer J Clin 66: 7-30, 2016.

2. Chen W, Zheng R, Baade PD, Zhang S, Zeng H, Bray F, Jemal A Yu XQ and He J: Cancer statistics in China, 2015. CA Cancer J Clin 66: 115-132, 2016.

3. Egan A, Dong Y, Zhang H, Qi Y, Balk SP and Sartor O: Castrationresistant prostate cancer: Adaptive responses in the androgen axis. Cancer Treat Rev 40: 426-433, 2014.

4. van Soest RJ, Nieuweboer AJ, de Morrée ES, Chitu D, Bergman AM, Goey SH, Bos MM, van der Meer N, Hamberg P, de Wit R, et al; Dutch Uro-Oncology Studygroup (DUOS): The influence of prior novel androgen receptor targeted therapy on the efficacy of cabazitaxel in men with metastatic castrationresistant prostate cancer. Eur J Cancer 51: 2562-2569, 2015.

5. Al Nakouzi N, Le Moulec S, Albigès L, Wang C, Beuzeboc $P$, Gross-Goupil M, de La Motte Rouge T, Guillot A, Gajda D, Massard C, et al: Cabazitaxel remains active in patients progressing after docetaxel followed by novel androgen receptor pathway targeted therapies. Eur Urol 68: 228-235, 2015.

6. Mezynski J,Pezaro C, Bianchini D,Zivi A, Sandhu S, Thompson E, Hunt J, Sheridan E, Baikady B, Sarvadikar A, et al: Antitumour activity of docetaxel following treatment with the CYP17A1 inhibitor abiraterone: Clinical evidence for cross-resistance? Ann Oncol 23: 2943-2947, 2012.

7. van Soest RJ, van Royen ME, de Morrée ES, Moll JM, Teubel W, Wiemer EA, Mathijssen RH, de Wit R and van Weerden WM: Cross-resistance between taxanes and new hormonal agents abiraterone and enzalutamide may affect drug sequence choices in metastatic castration-resistant prostate cancer. Eur J Cancer 49: 3821-3830, 2013.

8. Chung Moh M, Hoon Lee L and Shen S: Cloning and characterization of hepaCAM, a novel Ig-like cell adhesion molecule suppressed in human hepatocellular carcinoma. J Hepatol 42: 833-841, 2005

9. Xu B, He Y, Wu X, Luo C, Liu A and Zhang J: Exploration of the correlations between interferon- $\gamma$ in patient serum and HEPACAM in bladder transitional cell carcinoma, and the interferon- $\gamma$ mechanism inhibiting BIU-87 proliferation. J Urol 188: 1346-1353, 2012.

10. Xun C, Luo C, Wu X, Zhang Q, Yan L and Shen S: Expression of hepaCAM and its effect on proliferation of tumor cells in renal cell carcinoma. Urology 75: 828-834, 2010.

11. Jiang XL, Zhang Y, Tan B, Luo CL and Wu XH: Renal tumor-derived exosomes inhibit hepaCAM expression of renal carcinoma cells in a p-AKT-dependent manner. Neoplasma 61: 416-423, 2014.

12. Tao J, Liu Q, Wu X, Xu X, Zhang Y, Wang Q and Luo C: Identification of hypermethylation in hepatocyte cell adhesion molecule gene promoter region in bladder carcinoma. Int $\mathrm{J}$ Med Sci 10: 1860-1867, 2013.

13. Du HF, Ou LP, Lv CK, Yang X, Song XD, Fan YR, Wu XH and Luo CL: Expression of hepaCAM inhibits bladder cancer cell proliferation via a $\mathrm{Wnt} / \beta$-catenin-dependent pathway in vitro and in vivo. Cancer Biol Ther 16: 1502-1513, 2015.

14. Wang Q, Luo C, Wu X, Du H, Song X and Fan Y: hepaCAM and p-mTOR closely correlate in bladder transitional cell carcinoma and hepaCAM expression inhibits proliferation via an AMPK/mTOR dependent pathway in human bladder cancer cells. J Urol 190: 1912-1918, 2013.

15. Quan Z,He Y,Luo C,Xia Y,Zhao Y,Liu N and Wu X: Interleukin 6 induces cell proliferation of clear cell renal cell carcinoma by suppressing hepaCAM via the STAT3-dependent up-regulation of DNMT1 or DNMT3b. Cell Signal 32: 48-58, 2017.

16. Zhang T, Moh MC, Lee LH and Shen S: The immunoglobulinlike cell adhesion molecule hepaCAM is cleaved in the human breast carcinoma MCF7 cells. Int J Oncol 37: 155-165, 2010.

17. Song X, Wang Y, Du H, Fan Y, Yang X, Wang X, Wu X and Luo C: Overexpression of HepaCAM inhibits cell viability and motility through suppressing nucleus translocation of androgen receptor and ERK signaling in prostate cancer. Prostate 74: 1023-1033, 2014.

18. Guruharsha KG, Kankel MW and Artavanis-Tsakonas S: The Notch signalling system: Recent insights into the complexity of a conserved pathway. Nat Rev Genet 13: 654-666, 2012.

19. Kwon OJ, Valdez JM, Zhang L, Zhang B, Wei X, Su Q, Ittmann MM, Creighton CJ and Xin L: Increased Notch signalling inhibits anoikis and stimulates proliferation of prostate luminal epithelial cells. Nat Commun 5: 4416, 2014. 
20. Bin Hafeez B, Adhami VM, Asim M, Siddiqui IA, Bhat KM Zhong W, Saleem M, Din M, Setaluri V and Mukhtar H: Targeted knockdown of Notch1 inhibits invasion of human prostate cancer cells concomitant with inhibition of matrix metalloproteinase-9 and urokinase plasminogen activator. Clin Cancer Res 15: 452-459, 2009

21. Santagata S, Demichelis F, Riva A, Varambally S, Hofer MD, Kutok JL, Kim R, Tang J, Montie JE, Chinnaiyan AM, et al: JAGGED1 expression is associated with prostate cancer metastasis and recurrence. Cancer Res 64: 6854-6857, 2004.

22. Cui D, Dai J, Keller JM, Mizokami A, Xia S and Keller ET: Notch pathway inhibition using PF-03084014, a $\gamma$-secretase inhibitor (GSI), enhances the antitumor effect of docetaxel in prostate cancer. Clin Cancer Res 21: 4619-4629, 2015.

23. Guo Y, Zhang K, Cheng C, Ji Z, Wang X, Wang M, Chu M, Tang DG, Zhu HH and Gao WQ: Numb ${ }^{-/ l o w}$ enriches a castrationresistant prostate cancer cell subpopulation associated with enhanced notch and hedgehog signaling. Clin Cancer Res 23: 6744-6756, 2017.

24. Stoyanova T, Riedinger M, Lin S, Faltermeier CM, Smith BA, Zhang KX, Going CC, Goldstein AS, Lee JK, Drake JM, et al: Activation of Notch1 synergizes with multiple pathways in promoting castration-resistant prostate cancer. Proc Natl Acad Sci USA 113: E6457-E6466, 2016.

25. Wang Y, Wu X, Ou L, Yang X, Wang X, Tang M, Chen E and Luo C: PLCe knockdown inhibits prostate cancer cell proliferation via suppression of Notch signalling and nuclear translocation of the androgen receptor. Cancer Lett 362: 61-69, 2015.

26. Wei P, Walls M, Qiu M, Ding R, Denlinger RH, Wong A, Tsaparikos K, Jani JP, Hosea N, Sands M, et al: Evaluation of selective gamma-secretase inhibitor PF-03084014 for its antitumor efficacy and gastrointestinal safety to guide optimal clinical trial design. Mol Cancer Ther 9: 1618-1628, 2010.

27. Yabuuchi S, Pai SG, Campbell NR, de Wilde RF, De Oliveira E, Korangath P, Streppel MM, Rasheed ZA, Hidalgo M, Maitra A, et al: Notch signaling pathway targeted therapy suppresses tumor progression and metastatic spread in pancreatic cancer. Cancer Lett 335: 41-51, 2013.

28. Arcaroli JJ, Quackenbush KS, Purkey A, Powell RW, Pitts TM, Bagby S, Tan AC, Cross B, McPhillips K, Song EK, et al: Tumours with elevated levels of the Notch and Wnt pathways exhibit efficacy to PF-03084014, a $\gamma$-secretase inhibitor, in a preclinical colorectal explant model. Br J Cancer 109: 667-675, 2013.

29. Heidenreich A, Bastian PJ, Bellmunt J, Bolla M, Joniau S, van der Kwast T, Mason M, Matveev V, Wiegel T, Zattoni F, et al; European Association of Urology: EAU guidelines on prostate cancer. Part II: Treatment of advanced, relapsing, and castration-resistant prostate cancer. Eur Urol 65: 467-479, 2014.

30. Matei DV, Renne G, Pimentel M, Sandri MT, Zorzino L, Botteri E, De Cicco C, Musi G, Brescia A, Mazzoleni F, et al: Neuroendocrine differentiation in castration-resistant prostate cancer: A systematic diagnostic attempt. Clin Genitourin Cancer 10: 164-173, 2012.

31. Livak KJ and Schmittgen TD: Analysis of relative gene expression data using real-time quantitative PCR and the 2(- $\Delta \Delta \mathrm{C}(\mathrm{T}))$ method. Methods 25: 402-408, 2001.

32. Kuruma H, Matsumoto H, Shiota M, Bishop J, Lamoureux F, Thomas C, Briere D, Los G, Gleave M, Fanjul A, et al: A novel antiandrogen, compound 30, suppresses castration-resistant and MDV3100-resistant prostate cancer growth in vitro and in vivo. Mol Cancer Ther 12: 567-576, 2013

33. Kawata H, Ishikura N, Watanabe M, Nishimoto A, Tsunenari T and Aoki Y: Prolonged treatment with bicalutamide induces androgen receptor overexpression and androgen hypersensitivity. Prostate 70: 745-754, 2010.

34. Kawabata R, Oie S, Oka T, Takahashi M, Kanayama $\mathrm{H}$ and Itoh $\mathrm{K}$ : Hydroxyflutamide enhances cellular sensitivity to 5-fluorouracil by suppressing thymidylate synthase expression in bicalutamideresistant human prostate cancer cells. Int J Oncol 38: 665-676, 2011.

35. Takeda M, Mizokami A, Mamiya K, Li YQ, Zhang J, Keller ET and Namiki M: The establishment of two paclitaxel-resistant prostate cancer cell lines and the mechanisms of paclitaxel resistance with two cell lines. Prostate 67: 955-967, 2007.

36. Govindan SV, Cardillo TM, Moon SJ, Hansen HJ and Goldenberg DM: CEACAM5-targeted therapy of human colonic and pancreatic cancer xenografts with potent labetuzumabSN-38 immunoconjugates. Clin Cancer Res 15: 6052-6061, 2009.

37. Han SU, Kwak TH, Her KH, Cho YH, Choi C, Lee HJ, Hong S, Park YS, Kim YS, Kim TA, et al: CEACAM5 and CEACAM6 are major target genes for Smad3-mediated TGF-beta signaling. Oncogene 27: 675-683, 2008.
38. Kirshner J,Chen CJ,Liu P,Huang J and Shively JE: CEACAM1-4S, a cell-cell adhesion molecule, mediates apoptosis and reverts mammary carcinoma cells to a normal morphogenic phenotype in a 3D culture. Proc Natl Acad Sci USA 100: 521-526, 2003

39. Weigelt B, Ghajar CM and Bissell MJ: The need for complex 3D culture models to unravel novel pathways and identify accurate biomarkers in breast cancer. Adv Drug Deliv Rev 69-70: 42-51, 2014.

40. Stubblefield K, Chean J, Nguyen T, Chen CJ and Shively JE: The adaptor SASH1 acts through NOTCH1 and its inhibitor DLK1 in a 3D model of lumenogenesis involving CEACAM1. Exp Cell Res 359: 384-393, 2017.

41. Danza G, Di Serio C, Ambrosio MR, Sturli N, Lonetto G, Rosati F, Rocca BJ, Ventimiglia G, del Vecchio MT, Prudovsky I, et al: Notch3 is activated by chronic hypoxia and contributes to the progression of human prostate cancer. Int J Cancer 133: 2577-2586, 2013.

42. Zhu H, Zhou X, Redfield S, Lewin J and Miele L: Elevated Jagged-1 and Notch-1 expression in high grade and metastatic prostate cancers. Am J Transl Res 5: 368-378, 2013.

43. Domingo-Domenech J, Vidal SJ, Rodriguez-Bravo V, Castillo-Martin M, Quinn SA, Rodriguez-Barrueco R, Bonal DM, Charytonowicz E, Gladoun N, de la Iglesia-Vicente J, et al: Suppression of acquired docetaxel resistance in prostate cancer through depletion of notch- and hedgehog-dependent tumor-initiating cells. Cancer Cell 22: 373-388, 2012.

44. Zhang QL, Luo CL, Wu XH, Wang CY, Xu X, Zhang YY, Liu Q and Shen SL: HepaCAM induces G1 phase arrest and promotes c-Myc degradation in human renal cell carcinoma. J Cell Biochem 112: 2910-2919, 2011.

45. Tang M, Zhao Y, Liu N, Chen E, Quan Z, Wu X and Luo C: Overexpression of HepaCAM inhibits bladder cancer cell proliferation and viability through the AKT/FoxO pathway. J Cancer Res Clin Oncol 143: 793-805, 2017.

46. Wu M, Moh MC and Schwarz H: HepaCAM associates with connexin 43 and enhances its localization in cellular junctions. Sci Rep 6: 36218, 2016.

47. Yap TA, Smith AD, Ferraldeschi R, Al-Lazikani B, Workman P and de Bono JS: Drug discovery in advanced prostate cancer: Translating biology into therapy. Nat Rev Drug Discov 15: 699-718, 2016.

48. Sharp A, Welti J, Blagg J and de Bono JS: Targeting androgen receptor aberrations in castration-resistant prostate cancer. Clin Cancer Res 22: 4280-4282, 2016.

49. Tannock IF, de Wit R, Berry WR, Horti J, Pluzanska A, Chi KN, Oudard S, Théodore C, James ND, Turesson I, et al; TAX 327 Investigators: Docetaxel plus prednisone or mitoxantrone plus prednisone for advanced prostate cancer. N Engl J Med 351: 1502-1512, 2004.

50. Zhang CC, Pavlicek A, Zhang Q, Lira ME, Painter CL, Yan Z, Zheng X, Lee NV, Ozeck M, Qiu M, et al: Biomarker and pharmacologic evaluation of the $\gamma$-secretase inhibitor PF-03084014 in breast cancer models. Clin Cancer Res 18: 5008-5019, 2012

51. Papayannidis C, DeAngelo DJ, Stock W, Huang B, Shaik MN, Cesari R, Zheng X, Reynolds JM, English PA, Ozeck M, et al: A Phase 1 study of the novel gamma-secretase inhibitor PF-03084014 in patients with T-cell acute lymphoblastic leukemia and T-cell lymphoblastic lymphoma. Blood Cancer J 5: e350, 2015.

52. Carol H, Maris JM, Kang MH, Reynolds CP, Kolb EA, Gorlick R, Keir ST, Wu J, Kurmasheva RT, Houghton PJ, et al: Initial testing (stage 1) of the notch inhibitor PF-03084014, by the pediatric preclinical testing program. Pediatr Blood Cancer 61: 1493-1496, 2014.

53. Kummar S, O'Sullivan Coyne G, Do KT, Turkbey B, Meltzer PS, Polley E, Choyke PL, Meehan R, Vilimas R, Horneffer Y, et al: Clinical activity of the $\gamma$-secretase inhibitor PF-03084014 in adults with desmoid tumors (aggressive fibromatosis). J Clin Oncol 35: 1561-1569, 2017.

54. Lombardo Y, Faronato M, Filipovic A, Vircillo V, Magnani L and Coombes RC: Nicastrin and Notch4 drive endocrine therapy resistance and epithelial to mesenchymal transition in MCF7 breast cancer cells. Breast Cancer Res 16: R62, 2014.

55. Yun J, Pannuti A, Espinoza I, Zhu H, Hicks C, Zhu X, Caskey M, Rizzo P, D'Souza G, Backus K, et al: Crosstalk between PKC $\alpha$ and Notch-4 in endocrine-resistant breast cancer cells. Oncogenesis 2: e60, 2013.

This work is licensed under a Creative Commons Attribution-NonCommercial-NoDerivatives 4.0 International (CC BY-NC-ND 4.0) License. 